\title{
Clinical Practice Guideline for Postoperative Rehabilitation in Older Patients With Hip Fractures
}

\author{
Kyunghoon Min, MD, PhD ${ }^{1}$, Jaewon Beom, MD, PhD², Bo Ryun Kim, MD, PhD ${ }^{3}$, Sang Yoon Lee, MD, $\mathrm{PhD}^{4}$, \\ Goo Joo Lee, $\mathrm{MD}^{5}$, Jung Hwan Lee, $\mathrm{MD}, \mathrm{PhD}^{6}$, Seung Yeol Lee, $\mathrm{MD}, \mathrm{PhD}^{7}$, Sun Jae Won, $\mathrm{MD}, \mathrm{PhD}^{8}$, \\ Sangwoo Ahn, $\mathrm{PT}^{9}$, Heui Je Bang, $\mathrm{MD}^{10}$, Yonghan Cha, $\mathrm{MD}, \mathrm{PhD}^{11}$, Min Cheol Chang, $\mathrm{MD}^{12}$, \\ Jung-Yeon Choi, MD, PhD ${ }^{13}$, Jong Geol Do, MD, $\mathrm{PhD}^{14}$, Kyung Hee Do, MD, PhD ${ }^{15}$, Jae-Young Han, MD, $\mathrm{PhD}^{16}$, \\ Il-Young Jang, $\mathrm{MD}^{17}$, Youri Jin, RD, PhD ${ }^{18}$, Dong Hwan Kim, MD, PhD $^{19}$, Du Hwan Kim, MD, PhD ${ }^{20}$, \\ In Jong Kim, $\mathrm{MD}^{21}$, Myung Chul Kim, PT, $\mathrm{PhD}^{22}$, Won Kim, $\mathrm{MD}, \mathrm{PhD}^{23}$, Yun Jung Lee, $\mathrm{MD}^{24}$, \\ In Seok Lee, RD, $\mathrm{PhD}^{25}$, In-Sik Lee, MD, $\mathrm{PhD}^{26}$, JungSoo Lee, MD, $\mathrm{PhD}^{27}$, Chang-Hyung Lee, MD, $\mathrm{PhD}^{28}$, \\ Seong Hoon Lim, MD, PhD ${ }^{29}$, Donghwi Park, MD, PhD $^{30}$, Jung Hyun Park, MD, PhD ${ }^{31}$, \\ Myungsook Park, RN, $\mathrm{PhD}^{32}$, Yongsoon Park, $\mathrm{PhD}^{33}$, Ju Seok Ryu, MD, PhD ${ }^{2}$, Young Jin Song, OT, $\mathrm{MS}^{34}$, \\ Seoyon Yang, $\mathrm{MD}, \mathrm{PhD}^{35}$, Hee Seung Yang, $\mathrm{MD}^{15}$, Ji Sung Yoo, $\mathrm{MD}, \mathrm{PhD}^{36}$, Jun-il Yoo, $\mathrm{MD}, \mathrm{PhD}^{37}$, \\ Seung Don Yoo, MD, PhD ${ }^{19}$, Kyoung Hyo Choi, MD, $\mathrm{PhD}^{23}$, Jae-Young Lim, MD, $\mathrm{PhD}^{2}$
}

\begin{abstract}
${ }^{1}$ Department of Rehabilitation Medicine, CHA Bundang Medical Center, CHA University School of Medicine, Seongnam; ${ }^{2}$ Department of Rehabilitation Medicine, Seoul National University College of Medicine, Seoul National University Bundang Hospital, Seongnam; ${ }^{3}$ Department of Physical Medicine and Rehabilitation, Anam Hospital, Korea University College of Medicine, Seoul; ${ }^{4}$ Department of Rehabilitation Medicine, Seoul National University College of Medicine, SMG-SNU Boramae Medical Center, Seoul; ${ }^{5}$ Department of Rehabilitation Medicine, Seoul National University Hospital, National Traffic Injury Rehabilitation Hospital, Yangpyeong; ${ }^{6}$ Namdarun Rehabilitation Clinic, Yongin; ${ }^{7}$ Department of Physical Medicine and Rehabilitation, Soonchunhyang University Hospital, Soonchunhyang University College of Medicine, Bucheon; ${ }^{8}$ Department of Rehabilitation Medicine, Yeouido Saint Mary's Hospital, College of Medicine, The Catholic University of Korea, Seoul; ${ }^{9}$ Physical
\end{abstract}

Received June 1, 2021; Revised June 10, 2021; Accepted June 10, 2021; Published online June 30, 2021 Corresponding author: Jae-Young Lim

Department of Rehabilitation Medicine, Seoul National University College of Medicine, Seoul National University Bundang Hospital, 82 Gumi-ro 173beon-gil, Bundang-gu, Seongnam 13620, Korea. Tel: +82-31-787-7732, Fax: +82-31-787-4056, E-mail: drlim1@snu.ac.kr

ORCID: Kyunghoon Min (http://orcid.org/0000-0003-3357-9795); Jaewon Beom (http://orcid.org/0000-0001-7984-9661); Bo Ryun Kim (http://orcid. org/0000-0001-7788-7904); Sang Yoon Lee (http://orcid.org/0000-0002-2906-3094); Goo Joo Lee (http://orcid.org/0000-0002-8436-4463); Jung Hwan Lee (http://orcid.org/0000-0003-2680-6953); gSeung Yeol Lee (http://orcid.org/0000-0003-1571-9408); Sun Jae Won (http://orcid.org/0000-00029057-3747); Sangwoo Ahn (http://orcid.org/0000-0002-3568-4428); Heui Je Bang (http://orcid.org/0000-0001-5280-122X); Yonghan Cha (http://orcid. org/0000-0002-7616-6694); Min Cheol Chang (http://orcid.org/0000-0002-7629-7213); Jung-Yeon Choi (http://orcid.org/0000-0001-5139-5346); Jong Geol Do (http://orcid.org/0000-0001-8001-7782); Kyung Hee Do (http://orcid.org/0000-0003-4235-8759); Jae-Young Han (http://orcid.org/0000-00031672-8875); Il-Young Jang (http://orcid.org/0000-0003-3617-3301); Youri Jin (http://orcid.org/0000-0002-3356-0085); Dong Hwan Kim (http://orcid. org/0000-0002-3812-5509); Du Hwan Kim (http://orcid.org/0000-0002-9980-8549); In Jong Kim (http://orcid.org/0000-0002-7143-6114); Myung Chul Kim (http://orcid.org/0000-0003-0826-6754); Won Kim (http://orcid.org/0000-0002-9331-9795); Yun Jung Lee (http://orcid.org/0000-0001-54155735); In Seok Lee (http://orcid.org/0000-0001-5218-8090); In-Sik Lee (http://orcid.org/0000-0001-8167-7168); JungSoo Lee (http://orcid.org/00000002-3807-4377); Chang-Hyung Lee (http://orcid.org/0000-0001-6460-6368); Seong Hoon Lim (http://orcid.org/0000-0002-5475-4153); Donghwi Park (http://orcid.org/0000-0002-7724-4682); Jung Hyun Park (http://orcid.org/0000-0003-3262-7476); Myungsook Park (http://orcid.org/0000-0003-17082789); Yongsoon Park (http://orcid.org/0000-0001-5110-5716); Ju Seok Ryu (http://orcid.org/0000-0003-3299-3038); Young Jin Song (http://orcid. org/0000-0003-0294-354X); Seoyon Yang (http://orcid.org/0000-0002-7522-1655); Hee Seung Yang (http://orcid.org/0000-0003-2492-7065); Ji Sung Yoo (http://orcid.org/0000-0003-3559-8412); Jun-il Yoo (http://orcid.org/0000-0002-3575-4123); Seung Don Yoo (http://orcid.org/0000-0003-45132560); Kyoung Hyo Choi (http://orcid.org/0000-0001-9137-3889); Jae-Young Lim (http://orcid.org/0000-0002-9454-0344).

@ This is an open-access article distributed under the terms of the Creative Commons Attribution Non-Commercial License (http://creativecommons.org/ licenses/by-nc/4.0) which permits unrestricted noncommercial use, distribution, and reproduction in any medium, provided the original work is properly cited. Copyright $\odot 2021$ by Korean Academy of Rehabilitation Medicine 
Therapy, Department of Rehabilitation Medicine, Seoul National University Bundang Hospital, Seongnam; ${ }^{10}$ Department of Rehabilitation Medicine, Chungbuk National University College of Medicine, Chungbuk National University Hospital, Cheongju; ${ }^{11}$ Department of Orthopaedic Surgery, Daejeon Eulji Medical Center, Eulji University School of Medicine, Daejeon; ${ }^{12}$ Department of Physical Medicine and Rehabilitation, Yeungnam University College of Medicine, Daegu; ${ }^{13}$ Department of Internal Medicine,

Seoul National University Bundang Hospital, Seoul National University College of Medicine, Seongnam; ${ }^{14}$ Department of Physical and Rehabilitation Medicine, Samsung Medical Center, Sungkyunkwan University School of Medicine, Seoul; ${ }^{15}$ Department

of Physical Medicine and Rehabilitation, Veterans Health Service Medical Center, Seoul; ${ }^{16}$ Department of Physical and Rehabilitation Medicine, Chonnam National University Medical School \& Hospital, Gwangju; ${ }^{17}$ Division of Geriatrics, Department of Internal Medicine, Asan Medical Center, University of Ulsan College of Medicine, Seoul; ${ }^{18}$ Department of Food and Nutrition Services, Hanyang University Hospital, Seoul; ${ }^{19}$ Department of Physical Medicine and Rehabilitation, Kyung Hee University Hospital at Gangdong, Seoul; ${ }^{20}$ Department of Physical Medicine and Rehabilitation, Chung-Ang University Hospital, ChungAng University College of Medicine, Seoul; ${ }^{21}$ Howareyou Rehabilitation Clinic, Seoul; ${ }^{22}$ Department of Physical Therapy, Eulji University, Seongnam; ${ }^{23}$ Department of Rehabilitation Medicine, Asan Medical Center, University of Ulsan College of Medicine, Seoul; ${ }^{24}$ Department of Physical Medicine and Rehabilitation, Myongji Hospital, Goyang; ${ }^{25}$ Nutrition Team, Kyung Hee University Medical Center, Seoul; ${ }^{26}$ Department of Rehabilitation Medicine, Konkuk University School of Medicine and Konkuk University Medical Center, Seoul; ${ }^{27}$ Department of Rehabilitation Medicine, Daejeon St. Mary's Hospital, College of Medicine, The Catholic University of Korea, Daejeon; ${ }^{28}$ Department of Physical Medicine and Rehabilitation, Pusan National University Yangsan Hospital, Pusan National University School of Medicine, Yangsan; ${ }^{29}$ Department of Rehabilitation Medicine, St. Vincent's Hospital, College of Medicine, The Catholic University of Korea, Suwon; ${ }^{30}$ Department of Physical Medicine and Rehabilitation, Ulsan University

Hospital, University of Ulsan College of Medicine, Ulsan; ${ }^{31}$ Department of Rehabilitation Medicine, Gangnam Severance

Hospital, Rehabilitation Institute of Neuromuscular Disease, Yonsei University College of Medicine, Seoul; ${ }^{32}$ Department of Nursing, Konkuk University, Chungju; ${ }^{33}$ Department of Food and Nutrition, Hanyang University, Seoul; ${ }^{34}$ Occupational Therapy, Department of Rehabilitation Medicine, Asan Medical Center, Seoul; ${ }^{35}$ Department of Rehabilitation Medicine, Ewha Woman's

University Seoul Hospital, Ewha Womans University School of Medicine, Seoul; ${ }^{36}$ Department of Rehabilitation Medicine, Research Institute and Hospital, National Cancer Center, Goyang; ${ }^{37}$ Department of Orthopaedic Surgery, Gyeongsang National University Hospital, Jinju, Korea

Objective The incidence of hip fractures is increasing worldwide with the aging population, causing a challenge to healthcare systems due to the associated morbidities and high risk of mortality. After hip fractures in frail geriatric patients, existing comorbidities worsen and new complications are prone to occur. Comprehensive rehabilitation is essential for promoting physical function recovery and minimizing complications, which can be achieved through a multidisciplinary approach. Recommendations are required to assist healthcare providers in making decisions on rehabilitation post-surgery. Clinical practice guidelines regarding rehabilitation (physical and occupational therapies) and management of comorbidities/complications in the postoperative phase of hip fractures have not been developed. This guideline aimed to provide evidence-based recommendations for various treatment items required for proper recovery after hip fracture surgeries.

Methods Reflecting the complex perspectives associated with rehabilitation post-hip surgeries, 15 key questions (KQs) reflecting the complex perspectives associated with post-hip surgery rehabilitation were categorized into four areas: multidisciplinary, rehabilitation, community-care, and comorbidities/complications. Relevant literature from four databases (PubMed, EMBASE, Cochrane Library, and KoreaMed) was searched for articles published up to February 2020. The evidence level and recommended grade were determined according to the grade of recommendation assessment, development, and evaluation method.

Results A multidisciplinary approach, progressive resistance exercises, and balance training are strongly recommended. Early ambulation, weigh-bearing exercises, activities of daily living training, community-level rehabilitation, management of comorbidities/complication prevention, and nutritional support were also suggested. This multidisciplinary approach reduced the total healthcare cost.

Conclusion This guideline presents comprehensive recommendations for the rehabilitation of adult patients after hip fracture surgery.

Keywords Hip fractures, Practice Guideline, Rehabilitation, Patient Care Team, Community Health Services 


\section{INTRODUCTION}

Hip fractures are common among older adults, with increasing incidences occurring as the population ages [1]. In 1997, there were 1.26 million hip fractures worldwide, which is expected to double in 2025 and reach 4.5 million in 2050 [2]. In a population-based study using the Korean National Health Insurance claims data, the annual incidence was 104.06 hip fractures (female 146.38 and male 61.72 ) per 100,000 people aged $\geq 50$ in 2003 [3].

The hip joint is located between the proximal femur and the acetabulum. A hip fracture refers to a fracture in the proximal femur that can be divided into femoral neck, intertrochanteric, and subtrochanteric fractures [4]. Hip fractures are classified as intracapsular or extracapsular fractures based on the relationship between the fracture site and the hip joint capsule. Since the joint capsule starts at the femoral neck and connects to the pelvis, femoral neck fractures are intracapsular, while intertrochanteric or subtrochanteric fractures are extracapsular [5]. As the period of immobilization after surgery increases, previous comorbidities worsen and new complications are likely to occur. Therefore, early rehabilitation treatment is essential for promoting postoperative recovery.

Hip fractures are common fragility fractures usually caused by low-energy trauma, such as falls, primarily in older people with osteoporosis [6]. Hip fractures result in high morbidity rates and seriously impair mobility and the ability to perform daily activities [7]. The mortality rate within one year after the occurrence of a hip fracture is reported to be $18 \%-31 \%$. In the long term, only half of the patients were able to walk without assistance and approximately one-fifth required care services [8]. Despite conventional rehabilitation treatments, significant mobility limitations have been reported [9]. With hip fractures, the life expectancy of people aged $>80$ years was shortened by 1.8 years, and the life expectancy of those with hip fractures decreased by $25 \%$ compared to the age-matched people without hip fractures [10]. When a hip fracture occurs in women aged $\geq 70$ years, the excess mortality rate is 9 per 100 patients [11]. In a study of hip fracture surgery (HFS) $(n=2,208)$, intensive rehabilitation after surgery significantly reduced the mortality rate at 6 months [12]. One study showed that $50 \%$ of postoperative deaths could be avoided [13]. As the population ages, more hip fractures occur, and the socioeconomic burden is increased $[14,15]$. Through rehabilitation treatment after HFS, gait, physical function, muscle strength, and balance were improved. The number of hospitalizations and frequency of falls also decreased [16].

\section{Appraisal of other clinical practice guidelines for hip} fracture rehabilitation

Clinical guidelines (CGs) focused on rehabilitation comprising physical and occupational therapies and the management of comorbidities/complications after HFS have not yet been developed. Currently accessible clinical practice guidelines (CPGs) that cover the diagnosis of hip fracture to surgery and postoperative rehabilitation include: National Institute for Health and Care Excellence (NICE) CG124 [17], Blue Book [18], Scottish Intercollegiate Guidelines Network (SIGN) 111, Scottish Standards of Care for Hip Fracture Patients [19,20], the guidelines of Australia and New Zealand Hip Fracture Registry and National Health and Medical Research Council [21,22], and the Agency for Health Research and Quality (AHRQ) of the United States [23]. Postoperative rehabilitation guidelines were referred from these to develop the current guidelines (Table 1). A CPG for physical therapy in older adults with hip fractures was recently published [24].

\section{Purpose of CPGs}

This guideline presents evidence for fracture rehabilitation proven by scientific methods to clinicians and other healthcare professionals. We aimed to systematically provide the information necessary for decision-making on issues related to hip fracture rehabilitation: (1) the importance of multidisciplinary management after HFS, (2) components and effects of rehabilitative treatments after HFS, (3) community-based rehabilitation following intensive rehabilitation after HFS, and (4) combined medical problems after HFS (pain, venous thrombosis, urinary tract infection [UTI], osteoporosis, and nutrition). The guideline will contribute to restoring maximum mobility and physical ability, improving the quality of life (QoL), and ultimately reducing the refracture and mortality rates in patients who undergo HFS.

\section{Scope of CPG}

Rehabilitation treatment after HFS in adults was presented with physical and occupational therapies, and the issues related to community care, associated comorbidi- 


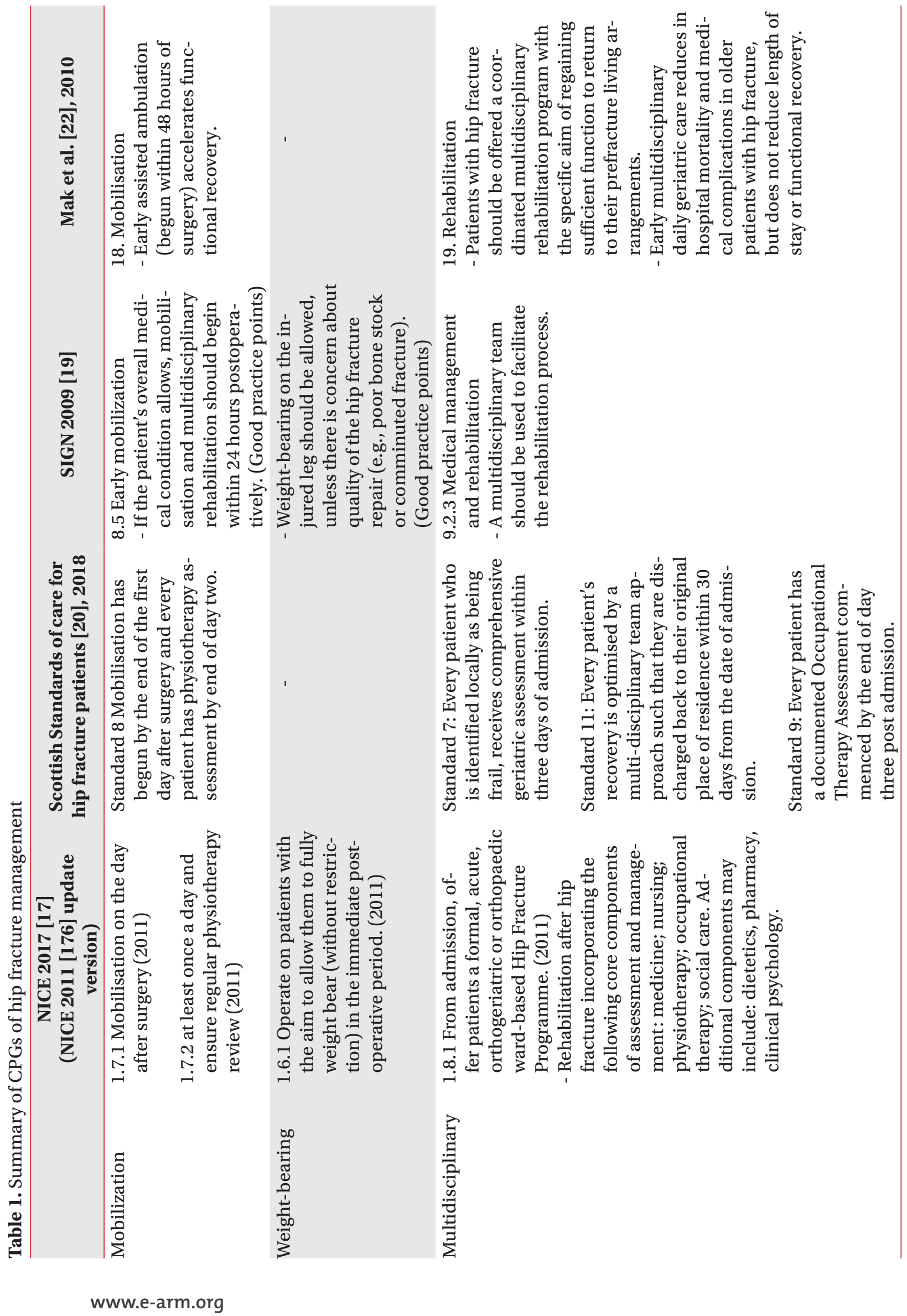




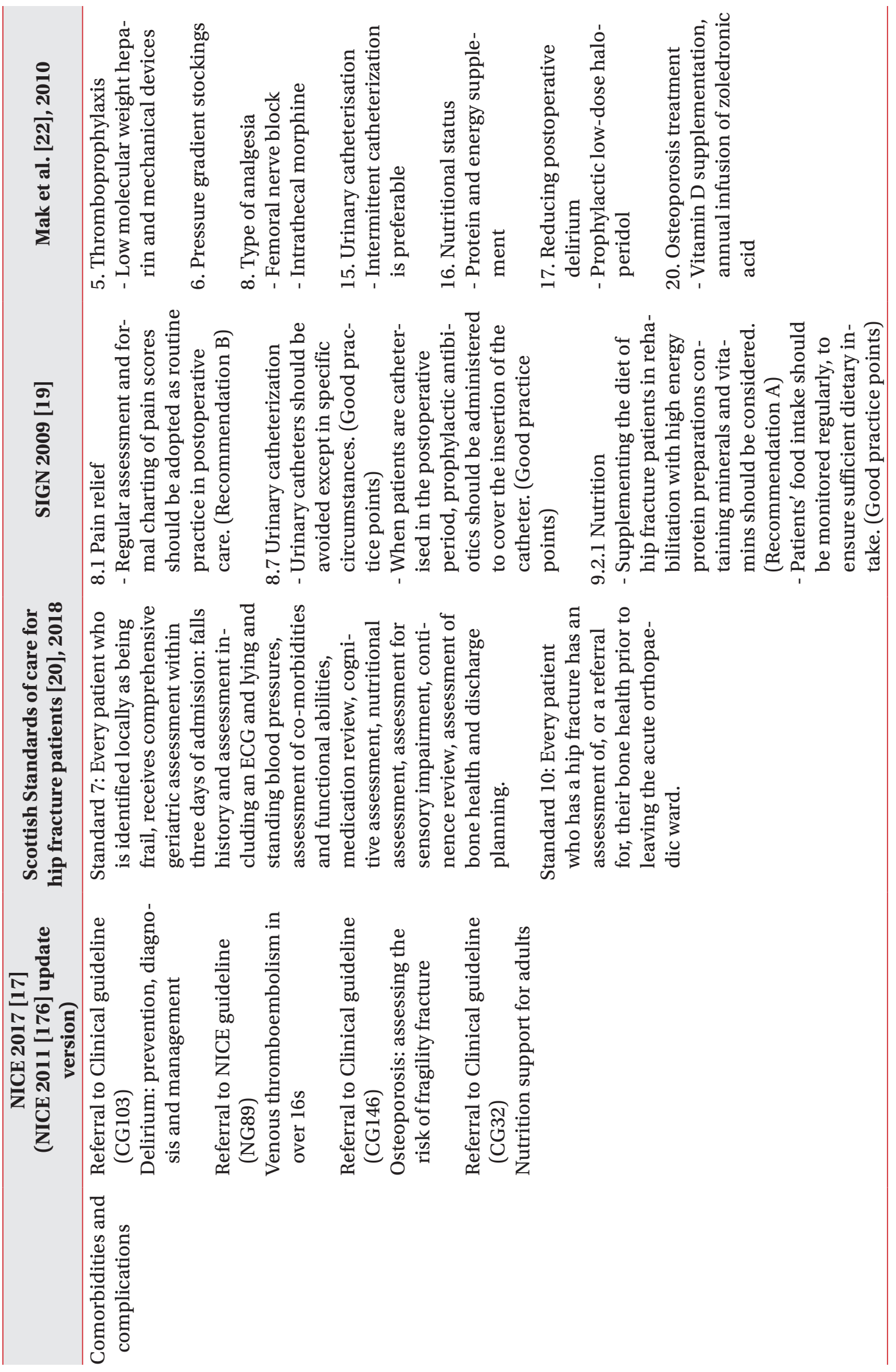




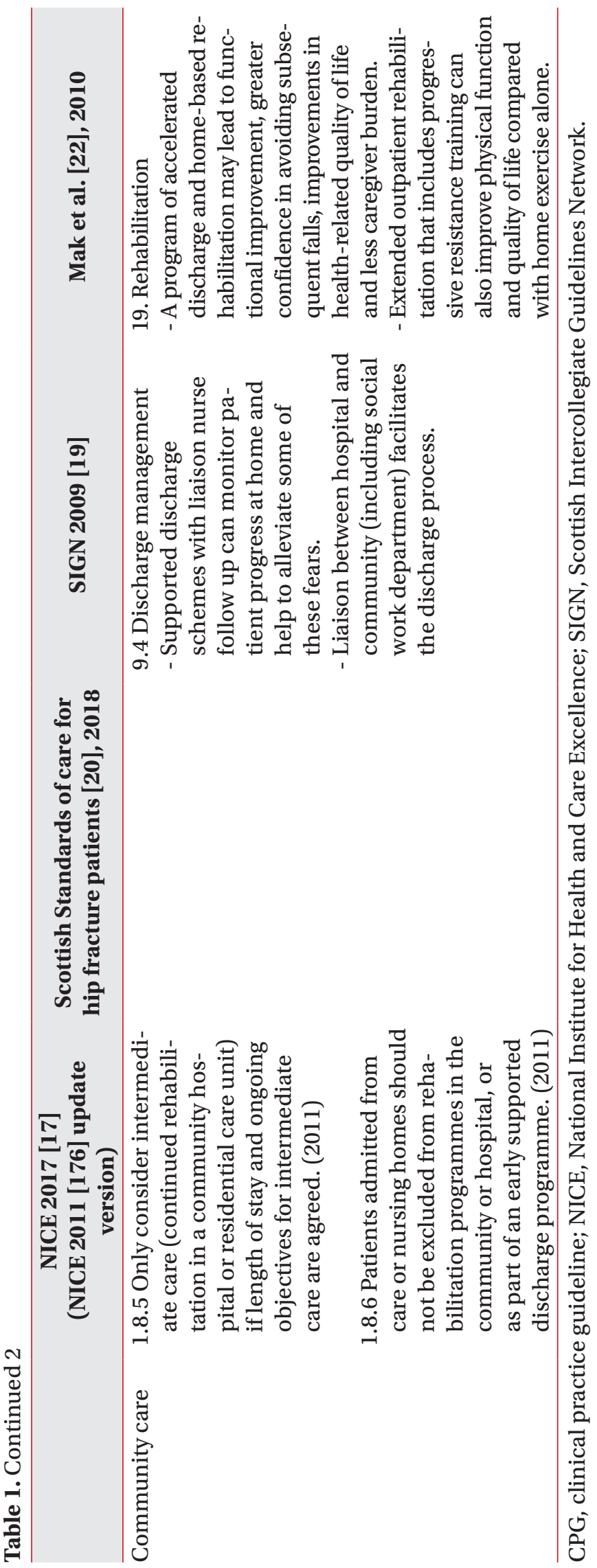

ties, complications, and nutrition were also addressed. Diagnosis and surgical techniques for hip fractures, metastatic fractures due to tumors, and pediatric fractures were not covered. This guideline does not limit physicians' medical practices and is not used to evaluate them.

\section{METHODS}

\section{Acknowledgement and independence}

This guideline was developed with financial support from the Korean Academy of Rehabilitation Medicine (KARM) and the Korean Academy of Geriatric Rehabilitation Medicine (KAGRM). However, the development was not affected by the supporting academies and was not supported by other groups. All members involved in the development of the guideline (43 members of a development committee) had no conflicts of interest (COI) related to this study. The COI was required to indicate whether or not to be involved in the development of similar guidelines, employment, financial interests, and other potential interests.

\section{CPG development group}

The guideline development group consisted of a development committee, an advisor, and an advisory committee (two methodology experts and two geriatricians). Forty-three development committee members were responsible for determining the level of evidence and recommendation level for each key question (KQ), consisting of 36 physicians ( 34 physiatrists and 2 orthopedic surgeons), 3 nutritionists, 1 nursing staff, 1 occupational therapist, and 2 physical therapists.

\section{Formation of KOs}

Perspectives of the targets to be applied and the groups used

The Steering Committee prepared a draft by referring to questions related to rehabilitation from the previous guidelines for hip fracture treatment. In order to reflect the perspectives and preferences of patients and their guardians after HFS, the results of a questionnaire survey conducted on 152 patients ( $\geq 65$ years) at a university hospital from September 2016 to May 2017 were reviewed. They were interested in rehabilitation after surgery and were highly anxious about postoperative pain, treatment costs, falls, and refractures [25]. 
Moreover, in 2017, 15 orthopedic surgeons and rehabilitation physicians were surveyed regarding the perception of the rehabilitation process after HFS. The following two points were identified. First, most of them agreed that hip fracture rehabilitation was not well-organized due to low medical care costs and limited hospital stay, and second, they recognized the lack of collaboration in rehabilitation after HFS.

\section{PICO selection}

A total of $15 \mathrm{KQs}$ reflecting the perspectives of the guideline users and patients were created consisting of four categories: (1) multidisciplinary approach (1 KQ), (2) rehabilitation treatment (6 KQs), (3) community care (2 KQs), and (4) comorbidities/complications (6 KQs). The KQs were structured according to the population, intervention, control, and outcomes (PICO) principle and are summarized in Tables 2 and 3.

Previously, the effectiveness of HFS was evaluated in terms of mortality and surgical implant success directly related to surgery; however, comprehensive aspects should be considered because of the complex clinical features and complications of hip fractures [26]. When making PICOs, all items should be specific; an increase in sensitivity of the literature regarding the outcome of PICO is required. As to $10 \mathrm{KQs}$, such as multidisciplinary system (KQ1), rehabilitation treatment (KQ2, 3, 4, 5, 6), local community (KQ8, 9), and nutrition-related KQs $(\mathrm{KQ14}, 15)$, the outcomes were evaluated in various aspects, including functional recovery (lower extremity muscle strength, mobility ability, and physical ability), mortality, activities of daily living (ADLs), hospital stay, and living facilities after discharge. The outcomes of hip fracture rehabilitation were evaluated in five areas: (1) mobility, and physical performance, (2) QoL, (3) ADLs, (4) disease-specific scales, and (5) hip-specific scales [27].

Delirium is a common problem after HFS, but we decided to follow the 2019 treatment guidelines already developed (SIGN157, risk reduction and management of delirium, a national clinical guideline) [28]. Position change and aspiration pneumonia screening tests were excluded due to a lack of evidence. CPGs for venous thromboembolism (VTE) have been developed. VTE is a serious medical complication that could be directly related to mortality during rehabilitation after HFS, and the guidelines of the American College of Chest Physi- cians (ACCP) and the Korean Society on Thrombosis and Hemostasis (KSTH), which were evaluated according to AGREE-II, have been partly adapted for the contents regarding hip fracture surgeries $[29,30]$.

\section{Selection and grading of evidence}

A literature search was conducted on PubMed (https:// pubmed.ncbi.nlm.nih.gov/), EMBASE (http://embase. com), Cochrane Library (http://cochranelibrary.com), and one domestic database of KoreaMed (http://koreamed.org). MeSH (for PubMed and Cochrane Library) and Emtree (for Embase) terms were used after establishing a highly sensitive search strategy in combination with natural language (Supplementary Data 1).

Documents searched for each KQ were collected using EndNote. Two researchers per KQ selected articles and excluded the literature on hip fractures related to cancerous or pathological fractures. Furthermore, papers written in languages other than English and Korean, case reports, technical reports, and documents that existed only in abstract form were excluded. If opinions differed, an agreement was reached, or a final decision was made through arbitration by a third party (Supplementary Data 2).

The selected documents were subjected to a risk of bias assessment; Cochrane risk-of-bias (RoB) 2.0 (randomized controlled trials [RCTs]) and the risk-of-bias assessment tool for non-randomized studies (RoBANS) (non-RCTs) were used [31,32]. The methodological quality of the systematic reviews (SRs) was assessed using AMSTAR 2.0-a measurement tool to assess the methodological quality of systematic reviews [33]. The level of evidence and recommendation grade were determined according to the GRADE method (grading of recommendation assessment, development, and evaluation) [34]. For each KQ, if there was a recently published systematic review literature, the level of evidence was determined by combining the systematic review literature and subsequent randomized controlled studies. Systematic review documents were evaluated in an integrated manner considering included articles based on (1) study limitation according to the study design, (2) indirectness of evidence, (3) inconsistency of results, (4) the imprecision of results, and (5) publication bias $[35,36]$. In addition to the systematic review literature, randomized control studies and nonrandomized control studies also evaluated the degree of 


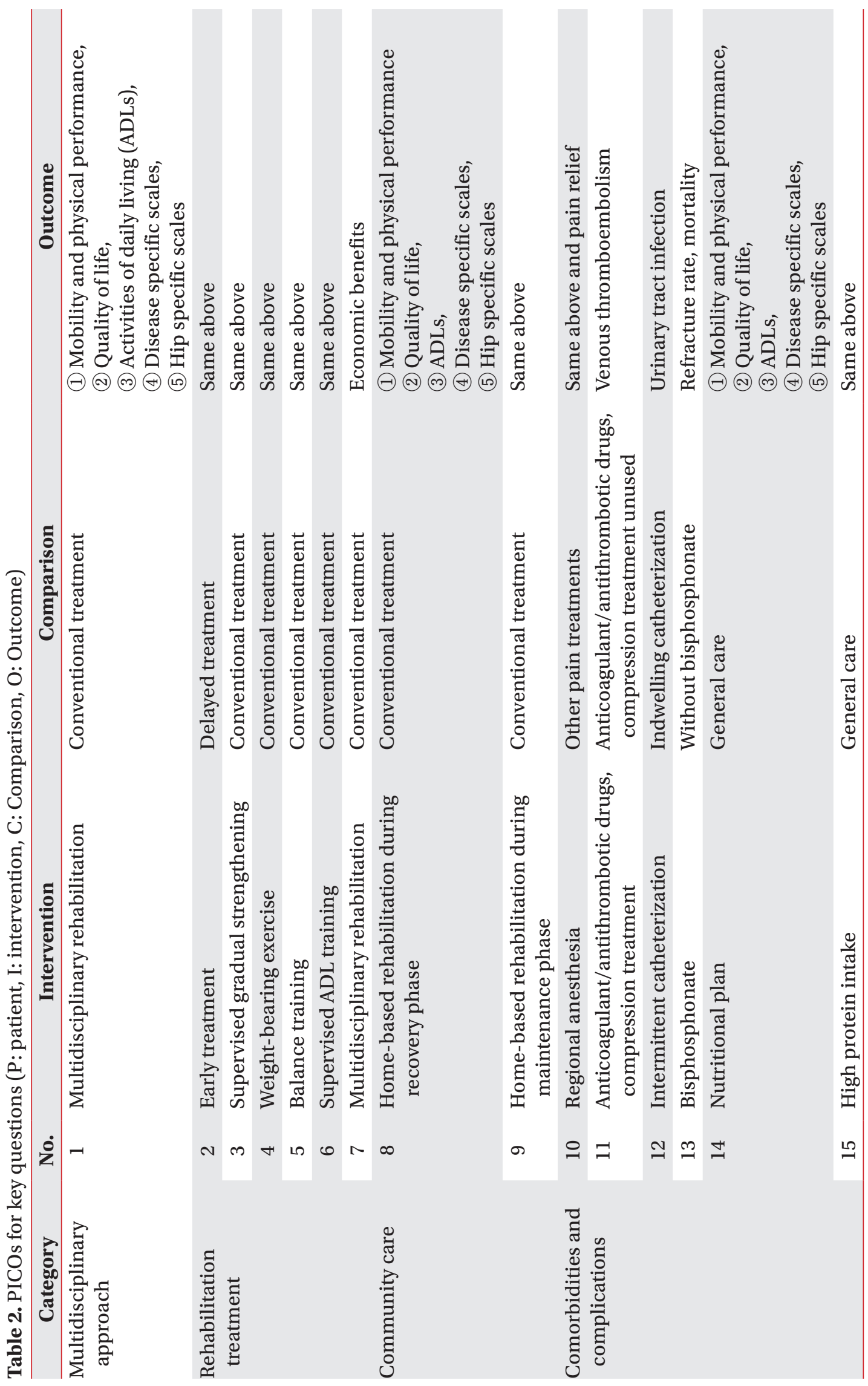


Table 3. Key questions (KQs) for clinical guidelines for postoperative rehabilitation after HFS

\begin{tabular}{|c|c|c|}
\hline No. & Questions \\
\hline KQ 1 & $\begin{array}{c}\text { Does hospital-based multidisciplinary rehabilitation have more clinical effects than usual postoperative } \\
\text { treatment in patients with HFS? }\end{array}$ \\
\hline KQ 2 & Is it functionally effective to start rehabilitation early (within 48 hours after surgery) after HFS? \\
\hline KQ 3 & Is supervised progressive resistance exercise more effective than self-directed exercise in patients with HFS? \\
\hline KQ 4 & Does weight-bearing exercise affect functional recovery after HFS? \\
\hline KQ 5 & After HFS, is rehabilitation treatment including balance exercise more effective than usual exercise? \\
\hline KQ 6 & Should ADLs training be included in rehabilitation treatment after HFS? \\
\hline KQ 7 & Is multidisciplinary rehabilitation treatment after HFS cost-effective? \\
\hline KQ 8 & Is home-based hip fracture rehabilitation effective during the recovery period after HFS? \\
\hline KQ 9 & Is home-based hip fracture rehabilitation effective during the maintenance period after HFS? \\
\hline KQ 10 & After HFS, can nerve block reduce postoperative pain? \\
\hline KQ 11 & After HFS, is the VTE prevention using compression therapy/drug treatment required? \\
\hline KQ 12 & Should the indwelling catheter be removed early after HFS to reduce UTI? \\
\hline KQ 13 & Can bisphosphonate administration reduce refracture and mortality after HFS? \\
\hline KQ 14 & After HFS, does nutritional evaluation and planning help functional recovery? \\
\hline KQ 15 & After HFS, does high protein supplementation help restore function? \\
\hline
\end{tabular}

HFS, hip fracture surgery; VTE, venous thromboembolism; ADLs, activities of daily living; UTI, urinary tract infection.

bias, consistency, directness, accuracy, and publication bias. The level of evidence for each KQ was finally determined as "high," "medium," "low," and "very low" according to the GRADE method.

After determining the level of evidence, the level of recommendation was determined by comprehensively considering the degree of certainty of the level of evidence, benefits and harms, allocation of cost resources, values and preferences, and domestic acceptability. If the evidence of treatment was insufficient, it was expressed as "hard to make a conclusion." If there was a basis for treatment, other factors necessary to determine the recommendation grade were expressed as "suggested" if the certainty was weak and "recommended" if the certainty was high. If the guidelines were included in the final selection document, the quality of the guidelines was evaluated with the Korean Appraisal of Guidelines for Research and Evaluation II [37]. As for the KQ about cost benefits, only the level of evidence was presented because it was not appropriate to determine the recommendation level. For each KQ, at least two members participated in all of the above processes and decisions were made through discussion (Supplementary Data 3).

\section{Formal consensus}

Formal consensus was achieved using the Delphi technique. From June 16 to June 25, 2020, the levels of evidence and recommendations were determined for 16 KQs. The degree of consent for each committee member was selected from 1 (non-acceptance) to 9 (acceptance) on a 9-point scale, and consent was obtained when the score was $\geq 7$. When at least $75 \%$ of the committee members agreed, it was deemed to have reached a consensus, and for items with less than $75 \%$ consensus, the Delphi survey was repeated and more than $75 \%$ consensus was reached. After two Delphi rounds, $1 \mathrm{KQ}$ did not reach an agreement (Is balance-specific exercise more effective than usual exercise after HFS?). Therefore, it was excluded from the KQs regarding CPG development. Finally, 15 recommendations were accepted.

\section{Distribution and implementation}

This guideline will be posted on the websites of the KARM, KAGRM, the Korean Society for Bone and Mineral Research, The Korean Geriatrics Society, the Korean Association of Pain Medicine, the Korea Physical Therapy Association, the Korean Association of Occupational Therapists, and the Korean Dietetic Association. Thereafter, summary booklets will be produced and distributed to members of the KARM. Since the degree of adherence to the treatment guidelines is related to the improvement of the patient's prognosis [38], this treatment guideline is 
continuously introduced in the promotional newsletters of the related academies. In the short term, the degree to which the guideline is used in the real-world environment can be assessed by the consultation status and time for rehabilitation after HFS. In the long term, it could be assessed by the degree of functional recovery after the distribution of CPGs and the change in mortality and refracture rates.

\section{Update of the CPG}

Efforts to establish and implement a national integrated management plan for fragility fracture care and prevention, such as Fracture Liaison Services (FLS), have been made in many countries $[39,40]$. Rehabilitation management for fragility fractures under the umbrella of FLS has been developed based on a systematic approach to fragility fracture care with the goal of restoring function and preventing subsequent fractures [41]. As a result, more evidence for hip fracture rehabilitation is expected. After regular meetings of the Clinical Guidelines Committee of KARM and obtaining approval from the Society's Board of Directors, we aim to make adaptations and accommodations of CPG every 5 years in cooperation with KAGRM.

\section{RESULTS}

\section{Summary of recommendation (Table 4)}

1. Multidisciplinary approach

KQ 1. Multidisciplinary rehabilitation is recommended in patients with HFS.
A. Evidence level: medium (4 SRs)
B. Grade of recommendation: strong

2. Rehabilitation

KQ 2. Early rehabilitation is suggested after HFS.

A. Evidence level: low (1 RCT), very low (5 nonRCTs)

B. Grade of recommendation: weak

KQ 3. Supervised PRE is recommended in patients with HFS.
A. Evidence level: medium (1 SR), low (2 RCTs)
B. Grade of recommendation: strong

KQ 4. Weight-bearing exercise is suggested after HFS.
A. Evidence level: medium (1 RCT), very low (10 non-RCTs)
B. Grade of recommendation: weak

KQ 5. Balance exercises should be included in rehabilitation treatment after HFS.
A. Evidence level: medium (2 SRs)
B. Grade of recommendation: strong

KQ 6. After HFS, we suggest ADL training for rehabilitation treatment.
A. Evidence level: medium (1 SR), very low (1 non-RCT)
B. Grade of recommendation: weak

KQ 7. After HFS, multidisciplinary rehabilitation treatment is cost-effective.
A. Evidence level: low (3 RCTs)
B. Grade of recommendation: not applicable

3. Community care

KQ 8. We suggest a home-based hip fracture rehabilitation in the recovery phase after HFS.
A. Evidence level: very low (2 SRs), low (7 RCTs)
B. Grade of recommendation: weak

KQ 9. We suggest a home-based hip fracture rehabilitation in the maintenance phase after HFS.
A. Evidence level: low (4 RCTs)
B. Grade of recommendation: weak

4. Co-morbidities/complications

KQ 10. Peripheral nerve blocks are suggested to relieve postoperative pain after HFS.
A. Evidence level: low (6 RCTs)
B. Grade of recommendation: weak

KQ 11. After HFS, compression therapy/drug treatment is suggested to prevent VTE.

A. Evidence level: 2 CPGs (acceptable), high (1 SR), low (2 RCTs)

B. Grade of recommendation: weak

KQ 12. After HFS, the indwelling catheter is suggested to be removed as early as possible.

A. Evidence level: 1 CPG (acceptable), very low (3 RCTs)

B. Grade of recommendation: weak

KQ 13. After HFS, bisphosphonate administration is suggested to reduce refracture and mortality.
A. Evidence level: low (2 SRs)
B. Grade of recommendation: weak

KQ 14. After HFS, nutritional evaluation and planning are suggested for functional recovery.

A. Evidence level: low (1 SR), low (2 RCTs), very 


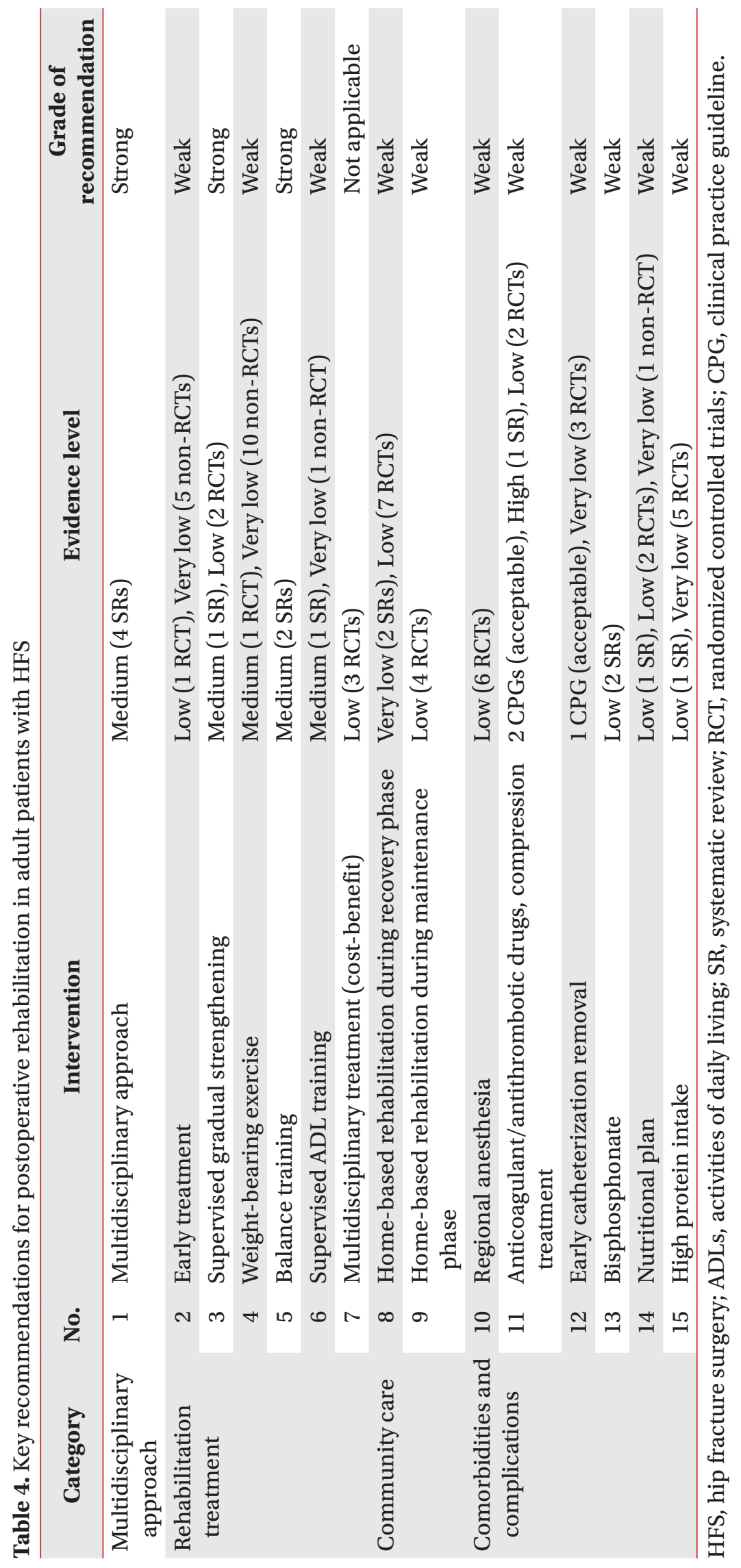


low (1 non-RCT)

B. Grade of recommendation: weak

KQ 15. After HFS, it is suggested to provide high protein supplementation for functional recovery.

A. Evidence level: low (1 SR), very low (5 RCTs)

B. Grade of recommendation: weak

\section{Multidisciplinary approach}

KQ 1. Does hospital-based multidisciplinary rehabilitation have more clinical effects than usual postoperative treatment in patients with HFS?

Most hip fractures are surgically treated. Comprehensive geriatric care from the geriatric perspective is a crucial approach for hip fracture, a common fragility fracture in older adults [42]. Traditionally, the postoperative management for hip fractures also includes orthopedic surgery without additional geriatric evaluations [26]. Since the incidence of complications such as delirium, pneumonia, and pressure injuries after HFS is as high as $75 \%$ [43], the management of hip fractures in older adults also requires interventions related to geriatric care [44]. Due to the characteristics of hip fractures that occur frequently in old age, there are many cases of various comorbidities/complications that affect the prognosis after surgery [26]. Rather than surgery-related complications, such as wound infections, aggravated frailty after hip fracture is believed to result in high complications and mortality. Hence, an integrated multidisciplinary team including orthopedic surgery, geriatric evaluations, and rehabilitation medicine is required to manage these poor outcomes [45]. For a multidisciplinary approach, it is also beneficial to reorganize existing resources [44]. Comprehensive multidisciplinary treatment improved gait function more than usual treatment at 4 and 12 months after surgery [46]. The model for providing multidisciplinary treatment after HFS can be classified into (1) orthopedic ward and geriatric consultant service on request, (2) orthopedic ward and daily geriatric consultative service, (3) geriatric/rehabilitation ward and orthopedic consultant service, and (4) orthopedic ward and integrated care [47]. The integrated care was also distinguished by the physicians in charge of dominant care: (1) orthopedic surgeon leadership in orthopedic ward $(A=$ traditional model: consultative medical service on request, $\mathrm{B}=$ consultant team: programmed consultant service), (2) no leading leadership in orthopedic ward (C=interdisciplinary/clini- cal pathway), (3) geriatric leadership in geriatric/rehabilitative ward $(\mathrm{D}=$ =geriatric-led fracture service, orthopedic surgeon consultant), and (4) orthopedic-geriatric leadership in orthogeriatric unit (E=geriatric co-managed care, interdisciplinary team) [48].

In a meta-analysis study (7 RCTs comparing usual postoperative care and geriatric multidisciplinary or interdisciplinary treatment in hip fracture patients aged $\geq 65$ years, total patients 1,763 ), geriatric interdisciplinary care showed significantly greater improvement in two domains (ADLs and mobility function) with standardized mean differences of 0.32 (95\% confidence interval [CI], $0.17-0.47$ ) and 0.32 (95\% CI, 0.12-0.52), respectively, than that with conventional care. No significant changes were found in the other two domains (the rate of living in one's home and survival rate). Through a multidisciplinary approach, ADL and mobility improved by approximately $13 \%$ (risk of heterogeneity, low $\left[\mathrm{I}^{2}=9 \%\right]$ ) and approximately $13 \%$ (risk of heterogeneity, moderate $\left[\mathrm{I}^{2}=55 \%\right]$ ) four months after surgery. Outcomes such as the chance of living at home ( $1 \%$ better in the intervention group) and survival ( $2 \%$ increase in the intervention group) showed good, but non-significant, trends in the intervention group [49]. A meta-analysis by Bachmann et al. [50] (9 studies; 1,853 participants included orthopedic geriatric rehabilitation) presented that the orthopedic geriatric rehabilitation resulted in higher ADL (Katz index and Barthel index) (odds ratio $[\mathrm{OR}]=2.33$; 95\% CI, 1.62-3.34) and lower rate of admission to nursing homes (relative risk $[\mathrm{RR}]=0.72 ; 95 \% \mathrm{CI}, 0.56-0.91)$ than those in the control group at discharge. Long term (3-12 month follow-up) observation also showed similar results: better function (OR=1.79; 95\% CI, 1.24-2.60) and decreased mortality rate ( $R R=0.77$; 95\% CI, 0.61-0.96). As such, multidisciplinary treatment where orthopedic surgery, geriatric medicine, and rehabilitation departments all participate is ideal. In a 2007 study of 11 studies (2,177 participants), the relative risk of poor prognosis (death or admission to a nursing home) at discharge was 0.84 in multidisciplinary treatment [51]. In another meta-analysis of 13 studies (2,498 participants), the multidisciplinary treatment group tended to decrease the relative risk of poor prognosis compared to the conventional control group for outcomes of mortality and residence status after 1 year [52].

Complex geriatric disorders in older patients with hip 
fractures can be managed effectively through comprehensive care. However, there is a risk of conflicting opinions among multidisciplinary experts in determining treatment directions. Multidisciplinary treatment can be successfully established with intimate cooperation among the departments of orthopedic surgery, rehabilitation, and/or geriatric medicine.

\section{Recommendation}

- Multidisciplinary rehabilitation is recommended in patients with HFS (evidence level: medium [4 SRs], grade of recommendation: strong).

\section{$K Q$ 2. Is it functionally effective to start rehabilitation} early (within 48 hours after surgery) after HFS?

The purpose of HFS is to reduce pain and provide early mobility training [18]. The NICE guideline for hip fracture management showed that early mobilization within 48 hours after surgery improved independence in transfer (moderate quality), walking distance (moderate quality), and reduced the assistance needed for walking on the seventh day after surgery. There were no differences in the discharge destination or mortality after discharge [17]. Other guidelines also recommended the initiation of early ambulation within 48 hours after surgery $[21,53]$. The incidence of pressure injuries can also be reduced by early ambulation. According to the literature, the definition of early timing at the start of rehabilitation treatment is slightly different (within 24 or 48 hours after surgery).

Sixty patients who underwent HFS were randomly assigned to the early ambulation group, who took their first walk within 2 days after the surgery, and into the delayed ambulation group, who took their first walk 3 and 4 days after surgery. The functional status on the 7th day after surgery was then compared. Compared to the delayed ambulation group (31 patients), the early ambulation group (19 patients) showed longer walking distance on the 7th day after surgery ( $82.55 \mathrm{~m}$ vs. $29.71 \mathrm{~m}$ ) and less dependence in transfer [54]. In a study of the National Hip Fracture Database in the UK, sitting or standing outside the bed within one day after surgery (early rehabilitation) led to improved walking ability at 30 days after surgery (data from 17,708 patients aged $\geq 60$ years with HFS from 2013 to 2015) [55]. In the same study, when the post-discharge condition was defined as 1 "death," 2 "worse," 3 "same," and 4 "better," the condition of pa- tients who received early rehabilitation improved after discharge [55]. There was no difference in whether mobilization was performed by physical therapists or those from other occupations [55]. In a retrospective study of 747 patients aged $\geq 65$ years who underwent HFS within 48 hours, in-hospital mortality rate was compared between the group who received mobility and strength training from the day after surgery (525 patients) and the group who received similar rehabilitation 2 or 3 days post-surgery (222 patients) [56]. The mortality rate was significantly high when the rehabilitation was started late (6.8 vs. $3.2 \%$; $\mathrm{OR}=2.2 ; 95 \% \mathrm{CI}, 1.06-4.42$ ) [56]. In another retrospective study (52 patients aged $>65$ years who underwent HFS, 23 patients who underwent early rehabilitation within one day after surgery and 29 patients who started rehabilitation later than 1 day after surgery), the early rehabilitation group showed a shorter hospital stay (5.4 vs. 6.9 days, $\mathrm{p}=0.026$ ). One month after surgery, the Harris score (84.0 vs. 71.1$)$ and the pain sub-score of the Harris score (36.8 vs. 24.4 ) was significantly improved with early treatment [57]. Among the three hospitals that performed HFS in patients aged $>75$ years, the model of early rehabilitation within 3 days after surgery and transfer/access to a rehabilitation facility after discharge resulted in less ADL loss and higher prediction of independent walking at 6 months post-surgery [58]. In addition, as walking training after HFS was delayed, the risk of pneumonia $(\mathrm{OR}=1.5, \mathrm{p}<0.001)$ or delirium $(\mathrm{OR}=1.7$, $\mathrm{p}<0.001$ ) and length of stay (about 5 days in the walking group within 3 days post-surgery vs. 9.9 days in the walking group after 4 days post-surgery) increased [59].

The degree of functional recovery that can be obtained through early rehabilitation after surgery is expected to be superior to that obtained by late rehabilitation. Randomized trials on this matter may cause ethical problems in the control group who did not receive early rehabilitation treatment. As a result, the certainty of the estimates may be weak. Early consultation and communication between orthopedic surgery and rehabilitation medicine is necessary to perform mobility training within 48 hours after surgery.

\section{Recommendation}

- Early rehabilitation is suggested after HFS (evidence level: low [1 RCT], very low [5 non-RCTs]; grade of recommendation: weak). 
$K Q$ 3. Is supervised progressive resistance exercise more effective than self-directed exercise in patients with HFS? Progressive resistance exercise (PRE) is a method of increasing the ability of muscles to create force [60]. Lower limb strength is closely related to mobility [61]. After HFS, the knee extension strength on the fractured side decreased by more than $50 \%$ of the strength from the opposite side [62]. DeLorme and Watkins [63] proposed three principles of PRE: (1) to perform a small number of repetitions until fatigue, (2) to allow sufficient rest between exercises for recovery, and (3) to increase the resistance as the ability to generate force increases. These principles are also maintained in the guidelines of the American College of Sports Medicine [64].

According to a meta-analysis study of eight randomized studies (587 participants), compared with conventional treatment, PRE significantly improved overall physical function (standardized mean difference $[S M D]=0.408 ; 95 \% \mathrm{CI}, 0.238-0.578 ; \mathrm{p}<0.001)$, overall mobility (SMD $=0.501 ; 95 \% \mathrm{CI}, 0.297-0.705 ; \mathrm{p}<0.001$ ), ADLs (SMD $=0.238 ; 95 \% \mathrm{CI}, 0.040-0.437 ; \mathrm{p}=0.019$ ), balance (SMD $=0.554 ; 95 \% \mathrm{CI}, 0.310-0.797 ; \mathrm{p}<0.001$ ), lower limb strength or power (SMD $=0.421 ; 95 \% \mathrm{CI}, 0.101-0.741$; $\mathrm{p}=0.010$ ) and performance tasks (SMD $=0.841 ; 95 \% \mathrm{CI}$, 0.197-1.484; $\mathrm{p}=0.010$ ). Self-reported physical function was not significant (SMD=0.449; 95\% CI, 0.061-0.958; $\mathrm{p}=0.084$ ) [65]. One hundred patients aged $70-84$ years old who underwent hemiarthroplasty surgery for femoral neck fracture (Garden's classification III or IV) were randomly allocated into the conventional strengthening plus intensive abductor strengthening group (strengthening hip abductor was added from the 4th week after surgery into the conventional exercise from day 2 after surgery) and the conventional exercise group (from day 2 after surgery) and followed up to 6 months after surgery. When hip abductor strength was additionally strengthened, the abduction muscle strength improved after 3 and 6 months of surgery by $35.7 \%$ and $37.0 \%$, respectively, compared with the conventional exercise group. The results of the Timed Up and Go tests were faster by $29.1 \%$ and $45.9 \%$, respectively [66]. In 90 patients over 65 years of age who underwent HFS, the addition of knee extensor strengthening training to their usual exercise increased the maximal velocity torque of the knee extensor by $8.1 \%$ as measured by a handheld dynamometer at the time of discharge or on the 10th day after surgery [67].

Supervised PRE can improve physical function more efficiently, although excessive exercise can cause delayedonset muscle pain. Due to the frailty and cognitive dysfunction in elderly patients with hip fractures, practical difficulties are inherent in the implementation of PRE training. Considering such difficulties, appropriate reimbursement for treatment should be considered in the health insurance system to accommodate it in clinical practice.

Recommendation

- Supervised PRE is recommended in patients with HFS (evidence level: medium [1 SR], low [2 RCTs]; grade of recommendation: strong).

\section{KQ 4. Does weight-bearing exercise affect functional re- covery after HFS?}

If there is no problem with the union of the fracture site after HFS, early weight-bearing is recommended (Good Practice Points, SIGN 2009) [19]. Although weight-bearing as tolerated (WBAT) is allowed after HFS, patients often limit weight-bearing on the operated limb even 4 months post-surgery [68]. After HFS, weight-bearing might be avoided to reduce complications and concerns about the stability of the fracture site, but the evidence for restricting weight-bearing is extremely insufficient [69]. When patients with hip fractures ( $\mathrm{n}=596, \geq 65$ years) were allowed to weight-bear immediately after surgery, the reoperation rate after 1 year was $3.4 \%$, which was comparable to other studies regardless of the weightbearing status [70]. Various surgical methods (internal fixation, hemiarthroplasty, and total hip arthroplasty) are used depending on the location, whether the fractured hip is displaced, and the patient's condition [71]. When internal fixation was performed, the rate of revision after 2 years $(0.6 \%$ in hemiarthroplasty vs. $5.4 \%$ in internal fixation) was higher than that after joint replacement [70]. In the American College of Surgeons National Surgical Improvement Quality Program (ACS NSQIP) database, 7,947 patients underwent surgery for hip fractures in 2016 (cephalomedullary nail procedure, 4,040 patients; sliding hip screw, 1,138 patients; hip hemiarthroplasty or internal fixation, 2,769 patients). In total, 5,845 patients (cephalomedullary nail procedure, 2,858 patients; 
sliding hip screw, 823 patients; hip hemiarthroplasty or internal fixation, 2,164 patients) underwent WBAT on day one after surgery, and the remaining 2,102 patients underwent WBAT later than 1 day after surgery (cephalomedullary nail procedure, 1,182 patients; sliding hip screw, 315 patients; hip hemiarthroplasty or internal fixation, 605 patients). Postoperative mortality and complications were compared at 30 days post-surgery. In the cephalomedullary nail procedure group, when WBAT was performed from day one postoperatively, the mortality rate at 30 days post-surgery was lower ( $\mathrm{OR}=0.532$; 95\% CI, 0.383-0.738; $\mathrm{p}<0.001)$. As for complications 30 days post-surgery, patients who started WBAT early from day 1 after surgery had fewer complications and shorter hospital stays (in the cephalomedullary nail or sliding hip screw surgery groups) [72]. In another study using the same database of the 4,918 patients who underwent HFS over the age of $60,3,668$ patients $(74.58 \%)$ started WBAT on day 1 after surgery, and 1,250 patients (25.42\%) restricted weight-bearing. The mortality rate and incidence of complications were significantly reduced in the group that started WBAT on day 1 after surgery [73]. The partial weight-bearing group (weight-bearing $<20 \mathrm{~kg}$; $\mathrm{n}=19$ ) showed a decreased Parker mobility score (range $0-9$, higher score indicates better mobility) (-5.32 vs. $-3.36, \mathrm{p}<0.001)$ and lower walking speed $(0.16 \mathrm{~m} / \mathrm{s}$ vs. 0.28 $\mathrm{m} / \mathrm{s}, \mathrm{p}=0.003)$ than the full weight-bearing group $(\mathrm{n}=22)$ on the day 5 after surgery in patients ( $>75$ years) with intramedullary nailing of the peri-trochanteric fracture $[74,75]$. Non-weight-bearing was negatively associated with the Functional Independence Measure (FIM) score after 1 year of HFS-full weight-bearing within 48 hours after surgery $(\mathrm{n}=119)$ and non-weight-bearing in the first 2-4 weeks postoperatively $(n=75)$ [76]. With full weightbearing, arthritis incidence ( $\mathrm{p}=0.021$ ) and comprehensive severity index at hospitalization (higher scores were associated with higher acuity and comorbidity; $\mathrm{p}=0.014$ ) were significantly lower in the data of 224 patients who underwent HFS at 18 sites [77]. In addition, in 331 patients who underwent HFS, the hospital stay was significantly shorter when WBAT was performed than when WB was restricted ( 26 days vs. 34 days, $p=0.04$ ) [69]. A total of 120 participants were randomly assigned to the weightbearing home exercise group $(\mathrm{n}=40)$, non-weight-bearing home exercise group (supine position; $n=40$ ), or no intervention group $(n=40)$ after the acute phase of HFS was completed. The groups were instructed to perform home training for 4 months. Balance ability and functional performance were significantly improved in the weightbearing exercise group [78].

Cemented hemiarthroplasty is recommended for elderly patients with unstable femoral neck fractures, which allow immediate weight-bearing post-surgery $[5,17,79]$. As with early rehabilitation, weight-bearing exercise is an essential factor, and randomized trials have not been sufficiently conducted due to a potential ethical problem for the control group. Therefore, the certainty of the estimate may be somewhat insufficient, but the benefit of treatment is expected to be high. However, excessive weight loading while the surgical site is unstable may interfere with the union of the surgical site. There are cases of limiting weight-bearing of the lower extremity after HFS [80]. Close consultations between orthopedic surgery and rehabilitation medicine are necessary to determine the timing and level of weight-bearing exercises by referring to the aspect of the hip fracture, the type of fracture surgery, and the findings at the time of surgery.

\section{Recommendation}

- Weight-bearing exercise is suggested after HFS (evidence level: medium [1 RCT], very low [10 non-RCTs]; grade of recommendation: weak).

\section{KQ 5. After HFS, is rehabilitation treatment, including} balance exercise, more effective than usual exercise?

The reduction in balance ability, which is prominent among older adults, is known to increase the falling risk by 2.9 times [81]. Therefore, balance exercises should be an essential element of rehabilitation to reduce refractures in patients with HFS [24]. As for balance exercises, various studies including stepping exercises, sit-tostand/lateral step up, and balance task-specific training, were included. In a meta-analysis involving eight RCTs and 752 participants, physical function was significantly improved when balance exercise was additionally performed within 1 year after surgery $(\mathrm{SMD}=0.390 ; 95 \% \mathrm{CI}$, 0.114-0.667; $p=0.006$ ) [82]. As the secondary efficacy items, when compared with conventional rehabilitation treatment, balance training added on rehabilitation resulted in better scores for gait (SMD $=0.195 ; 95 \% \mathrm{CI}$, 0.043-0.347; $\mathrm{p}=0.012$ ), muscle strength (SMD $=0.276 ; 95 \%$ CI, 0.122-0.429; $\mathrm{p}<0.001)$, daily activities $(\mathrm{SMD}=0.484$; 
95\% CI, 0.043-0.926; $\mathrm{p}=0.032$ ), and QoL ( $\mathrm{SMD}=0.602$; 95\% CI, 0.023-1.181; $\mathrm{p}=0.042$ ) [82]. In another metaanalysis involving nine RCTs and 872 participants, the overall function increased more in the rehabilitation plus balance exercise group ( $\mathrm{SMD}=0.59 ; 95 \% \mathrm{CI}, 0.25-0.93$; $\mathrm{p}=0.001$ ) [83]. In this analysis, it was also effective in improving gait, lower extremity muscle strength, ADLs, and health-related QoL [83].

\section{Recommendation}

- Balance exercises should be included in rehabilitation treatment after HFS (evidence level: medium [2 SRs]; grade of recommendation: strong).

\section{KQ 6. Should ADL training be included in rehabilitation treatment after HFS?}

Occupational therapy has been used in rehabilitation management after HFS. It includes different types of training to maintain independence in performing ADLs. The American Occupational Therapy Association has introduced occupational therapy practice guidelines for patients after HFS to provide strategies for early recovery of autonomy [84]. Patients and physicians have pursued more aggressive and ambitious objectives, such as returning patients to their prefracture ADL level and previous social settings, while the classical goals of HFS were to reduce mortality and refracture after hip fracture. However, the implementation rate of occupational therapy after HFS is not high [85]. Occupational therapy is often determined not by the preferences of patients but by physicians' preferences [85].

One meta-analysis included five RCT studies and 524 patients. There were some effects of daily life movement, motor function, and fall prevention, despite a lack of statistical significance. However, there were significant effects on patients' health perception and post-fall confidence (SMD=0.391; 95\% CI, 0.104-0.678; $\mathrm{p}=0.008$ ) [86]. In a retrospective study, $50.9 \%$ of 1,266 patients received occupational therapy during hospitalization, and it was found that the group who received occupational therapy had greater motor FIM efficiency (average 0.79 vs. 0.70; $\mathrm{p}=0.02$ ) and FIM effectiveness (average 0.49 vs. 0.41 ; $\mathrm{p}<0.01$ ) than the control group [85].

\section{Recommendation}

- After HFS, we suggest ADL training for rehabilitation treatment (evidence level: medium [1 SR], very low [1 non-RCT]; grade of recommendation: weak).

\section{KQ 7. Is multidisciplinary rehabilitation treatment after HFS cost-effective?}

Although it has been found that rehabilitation treatment after HFS has a clinical effect, additional medical expenses such as rehabilitation treatment, hospitalization, and nursing care are required. The cost of a hip fracture was estimated at US\$81,300 (KRW 98,462,430), about half of which was the cost of nursing care facilities [10]. In a systematic review based on 32 studies conducted in the United States, Europe, and Australia, the expenses due to falls, including hip fractures, amounted to approximately $1 \%$ of the total annual medical expenses and $0.07 \%-0.2 \%$ of the annual gross national product. High medical expenses are required for a single condition of hip fracture [87]. The cost of acute hospitalization might be higher for additional health resources for rehabilitation treatment after fracture surgery. However, in the long term, by shortening hospital stays and the total treatment period required for recovery, the total medical costs could be reduced. From April 2008 to December 2012, Prestmo et al. [88] randomized 397 hip fracture patients ( $\geq 70$ years) into a comprehensive geriatric care group $(n=198)$ and an orthopedic care (control) group $(\mathrm{n}=199)$. They were followed up for 5 days and at 1, 4, and 12 months after surgery. When comparing costs in both groups, the medical expenses during the hospital stay after surgery were $€ 11,868$ and $€ 9,537$ for the comprehensive treatment and control groups, respectively. Multidisciplinary treatment required $€ 2,331$ more $(\mathrm{p}<0.0001)$. However, there was no significant difference in the total cost during 1 year after discharge, including all health and care services $(\mathrm{p}=0.22)$. In addition, quality adjusted life years (QALY), which reflects both the survival period and the QoL aspect, was significantly higher in the multidisciplinary treatment group than the control group for 12 months ( 0.49 vs. 0.42, $\mathrm{p}=0.019$ ). Considering the threshold per QALY of $€ 62,500$, the intervention group was cost-effective with a $99 \%$ probability compared to the control group [88]. Milte et al. [89] presented the incremental cost-effectiveness ratio (ICER) both in the intervention group (individual nutrition and exercise program, physical therapist, and dietitian visits) and the control group (social visits) for 6 months. Starting within 2 weeks after surgery for 6 
months, a physical therapist and a dietitian visited the intervention group (86 patients) every other week without overlapping each other, and provided strength and balance training, nutritional therapy for energy and protein intake, while the control group (89 patients) received regular weekly visits to perform their usual exercise done during hospitalization even after discharge. The average ICER per QALY was A $\$ 28,350$, and the probability that the ICER was below the threshold $(A \$ 50,000)$ was approximately $50 \%$. In this study, weekly exercise and nutrition therapy instruction were more costly ( $\$ \$ 45,331$ vs. A $\$ 44.764)$, but the ICER was more efficient. Another randomized trial allocated 538 patients with HFS into physically oriented rehabilitation (187 patients), geriatric oriented (171 patients), or usual rehabilitation (180 patients) groups. Rehabilitation was performed for up to three weeks. After 12 months, the physical rehabilitation group (0.697) showed significantly improved 15D-instrument health-related QoL compared to the geriatric rehabilitation (0.586) and usual rehabilitation (0.594) groups ( $\mathrm{p}=0.008$ and $\mathrm{p}=0.009$, respectively). Costs were lower in the physical rehabilitation group, so physical rehabilitation was cost-effective (physical rehabilitation $€ 51,018$ vs. routine rehabilitation $€ 57,031$ at $100 \%$ of the home aid's salary; $\mathrm{p}=0.014$ ) [90].

Multidisciplinary rehabilitation treatment can reduce medical expenses for treatment and care for patients with HFS. However, the findings were from other countries, and cost-benefit analysis also needs to be performed in Korea. This will be a necessary process when considering the expansion of insurance coverage for rehabilitation treatment.

Recommendation

- After HFS, rehabilitation treatment is cost-effective (evidence level: low [3 RCTs], grade of recommendation: not applicable).

\section{KQ 8. Is home-based hip fracture rehabilitation effective during the recovery period after HFS?}

Rehabilitation of the acute phase after a hip fracture begins immediately after fracture surgery in an acute hospital. Intensive rehabilitation treatment is performed to improve gait, balance, and ADL. Afterward, rehabilitation of the recovery phase is accomplished through continuous hospitalization or outpatient treatment in rehabilitation hospitals or long-term care hospitals after discharge from acute hospitals, or through rehabilitation in various community settings such as long-term care facilities, homes, and healthcare centers. After routine rehabilitation treatment is completed, rehabilitation in the maintenance phase is mainly performed in community-based settings such as long-term care facilities or homes; otherwise, additional rehabilitation treatments are not performed. Several studies that reported functional recovery after hip fracture showed about $40 \%-60 \%$ of patients recovering gait level before fracture, and about $40 \%-70 \%$ of patients recovering basic daily activities performance [91]. It has also been reported that maximal functional recovery after a hip fracture occurs during the first 6 months after the fracture [92]. Among various community-based rehabilitation programs, home-based rehabilitation has been provided in the form of a program consisting of individual functional status evaluation, exercise prescription, training, and monitoring. There are many useful aspects to older patients who have limited use of rehabilitation facilities outside due to impaired mobility after hip fracture. In a review conducted by Stott and Handoll [93] in 2011, a study of the application effect of a home-based rehabilitation program in patients discharged from the hospital after HFS reported contradicting results depending on the type of exercise and the start time. According to a report published by the Australian-New Zealand Geriatrics Association in 2011, rehabilitation treatment after a hip fracture continues to be necessary even after discharge from the hospital in the acute phase. Home-based rehabilitation programs have benefits in the recovery of function, confidence in falls, improved QoL, and reduced burden on caregivers [94]. Therefore, through a systematic review of the hip fracture rehabilitation program targeted at the recovery period, it is necessary to suggest the right evidence and recommendations based on these results.

In a systematic review published in 2013, five randomized controlled studies were reviewed on the effectiveness of a home-based multidisciplinary rehabilitation program after HFS [95]. As a comparison group, one study established a group that implemented a hospitalbased multidisciplinary rehabilitation program. Four studies set a group that did not receive additional rehabilitation treatment after rehabilitation treatment in acute hospitals. The results showed that the group that 
performed the home-based multidisciplinary rehabilitation program showed a significant improvement in functional status and lower extremity muscle strength in the long- and short-term follow-up compared to the group without additional rehabilitation treatment. Five RCTs were reviewed in a systematic review published in 2011 about the effect of exercise therapy at home after HFS [96]. In this review, only studies that performed exercise therapy and, not multidisciplinary rehabilitation programs, were analyzed. As a comparison group, one study used inpatient rehabilitation treatment, two studies performed outpatient rehabilitation treatment, and two studies did not perform additional rehabilitation treatment after acute rehabilitation. The group that received home-based rehabilitation treatment and the group who received outpatient rehabilitation treatment showed improvement in health-related QoL compared to the group that did not receive rehabilitation treatment. Meanwhile, in the variables evaluating physical performance, it was reported that the outpatient rehabilitation group tended to improve more than the home-based rehabilitation group. In an RCT reporting on the effectiveness of a home-based multidisciplinary program for about a year, a home-based multidisciplinary program was conducted that combines variations of environmental risk factors at home, safe walking guides, and progressive exercise programs through home visits of 5-6 physical therapy sessions, and counseling [97]. During the 1-year follow-up period, it was reported that the level of physical activity was significantly improved and continued to be maintained. Milte et al. [89] conducted a cost-effective study of a home-based multidisciplinary rehabilitation program that combined exercise therapy and nutrition treatment for 6 months. The average medical cost when the home-based rehabilitation program was implemented was not significantly different from that when the social visit was conducted [89]. Thus, the results of this study suggested that a rehabilitation program that combines home visit services by physical therapists and nutritionists may be provided at a relatively low additional cost. In 2016, two multidisciplinary rehabilitation program models, including home-based rehabilitation therapy, were compared with models including hospital-based rehabilitation therapy alone [98]. As a multidisciplinary rehabilitation program model, the interdisciplinary care model included consultation with geriatrics, hospital- based rehabilitation treatment, discharge planning, and four months of home-based rehabilitation treatment; the comprehensive care model included elements of the interdisciplinary care model and 12 months of homebased rehabilitation treatment, fall prevention, nutrition, and psychological counseling. As a result of followup for 12 months, both intervention groups applying the multidisciplinary-based rehabilitation program model showed a significant improvement in the physical function domains of the health-related QoL compared to the control group. In particular, this study has significance as an effect model on the care continuum by applying a home-based rehabilitation program linked to a hospitalbased multidisciplinary rehabilitation program. In 2016, a study by Karlsson et al. [99] also attempted to prove the effectiveness of a home-based multidisciplinary rehabilitation program linked to a hospital-based multidisciplinary rehabilitation program regarding walking ability and hospital stay. Both the intervention and control groups received a hospital-based multidisciplinary rehabilitation program. After discharge, the intervention group received a home-based rehabilitation program provided by a multidisciplinary team consisting of physical therapists, occupational therapists, nurses, doctors, social workers, and nutritionists. The results showed that there was no significant difference in walking ability between the two groups, but the hospital stay of the intervention group was significantly shortened. This result may be explained by the fact that, unlike previous studies, this study included patients with cognitive decline including dementia and patients living in long-term care facilities. In 2014, Salpakoski et al. [100] reported a significant improvement in mobility, especially stair walking ability, which requires more leg muscle strength and balance than general gait function, after a home-based multidisciplinary rehabilitation program for 12 months. In a comparative study done in 2011 of the effects of a homebased exercise rehabilitation program for hip fracture patients, aerobic and progressive resistance exercises were performed through a health trainer's home visit for approximately 1 year. Time and calories spent on physical activities, including bone mineral density, muscle strength, and ADL performance ability, were evaluated. No significant difference was observed between the two groups, except that the time spent on physical activity in the intervention group was significantly higher than that 
in the control group [101]. The authors described that the results were affected by targeting patients with good function, who could walk and exercise independently at home from patient recruitment. In 1999, Tinetti et al. [102] reported the effect of a home-based multidisciplinary rehabilitation program linked to the on-site service of physical therapists and occupational therapists provided by home visiting services. There was no significant improvement in function between the two groups, except for the significant improvement in upper limb muscle strength 6 months postoperatively in the intervention group. It is considered that the control group also received the same home visiting service, including the physical therapist's on-site service, which would have affected the outcome.

The home-based hip fracture rehabilitation program in the recovery period is a program provided to improve gait, balance, and ADLs continuously after in-hospital rehabilitation. The risk of harm is low, and the relative benefits in function and QoL are high.

Although some foreign guidelines recommend community-based rehabilitation programs, it is necessary to consider cost resources for domestic application.

\section{Recommendation}

- We suggest a home-based hip fracture rehabilitation in the recovery phase after HFS (evidence level: very low [2 SRs], low [7 RCTs]; grade of recommendation: weak).

\section{KQ 9. Is home-based hip fracture rehabilitation effective} during the maintenance period after HFS?

After hip fracture, many older patients experience long-term functional limitations. One study on recovery of function after hip fracture revealed that maximal function recovery occurred mostly during the first 6 months after fracture, and that age affected prognosis. In contrast, studies on the effect of comorbidities on functional recovery after hip fracture suggested that patients with stroke had poor functional improvement at 1 year after fracture, requiring supervision at 12 months after rehabilitation $[91,92]$. With regard to the time point of significant recovery in several areas after hip fracture, dependence gradually decreased in most functional areas over the first year after fracture. However, recovery of depression, upper limb function, and cognitive function took approximately four months, and recovery of lower limb function took approximately 12 months [103]. In addition, studies have shown that about $50 \%$ of men and about $40 \%$ of women die or live in long-term care facilities 2 years after a hip fracture [104]. Subsequently, many hip fracture patients do not recover their ADL or walking ability before the fracture even after the conventional rehabilitation treatment is completed, and they remain deconditioned in many cases, resulting in significant socioeconomic burdens. As mentioned above, home-based rehabilitation programs have many useful aspects for older patients who have limitations in the use of rehabilitation facilities. The evaluation of the patient's functional status, exercise prescription, education, and monitoring were provided. Therefore, through a systematic review of the hip fracture rehabilitation program targeted at the maintenance period, it is necessary to suggest the right evidence and recommendations based on these results.

In 2014, the effect of a home exercise program under minimal supervision was reported for patients who completed conventional rehabilitation after a hip fracture [105]. During the 6-month study period, physical therapist visits were decreased to a maximum of four times. A rehabilitation program was applied that focused on functional exercise, such as sitting and rising from a chair or climbing stairs. As a result, functional mobility and performance of daily activities were significantly improved compared to the control group, and this improvement was maintained until three months after the completion of the study. A small randomized controlled study reported the effect of a 10-week home-based progressive resistance exercise program in patients about 6 months after hip fracture. Low-frequency electrical stimulation therapy and mental imagery were administered to the control group [106]. A physical therapist provided home visits in both groups. The intervention group showed significant improvement in lower extremity muscle strength, walking speed, endurance, and physical performance compared to those in the control group. In particular, the improved function was maintained until approximately one year after the fracture. In 2004, Sherrington et al. [78] reported the effects of home-based weight-bearing and non-weight-bearing exercises in 120 patients who completed routine rehabilitation after hip fracture. The physical therapist's visit was made only twice for exercise training and feedback; thus, there was a limitation that each patient's actual exercise intensity could not be accu- 
rately measured. However, the group that performed the weight-bearing exercise showed significant improvement in balance and functional performance compared to the group who performed non-weight-bearing exercise or the group who did not exercise at all. The authors suggested that the weight-bearing exercise in their study was closely related to the movements performed in actual daily life and showed good results even with minimal supervision. In 1997, a small-randomized study was conducted that reported the effect of home-based rehabilitation therapy. They reported that a simple home rehabilitation exercise program consisting of repeated simple weight-bearing movements using a thick telephone book showed improvement in lower extremity muscle strength, balance, and gait [107].

A home-based hip fracture rehabilitation program in the maintenance period is provided to improve gait, balance, and ADLs after the recovery period of rehabilitation. The risk of harm that may occur due to the intervention is substantially low. Benefits such as improved function and QoL are expected with home-based rehabilitation.

\section{Recommendation}

- We suggest a home-based hip fracture rehabilitation in the maintenance phase after HFS (evidence level: low [4 RCTs]; grade of recommendation: weak).

\section{KQ10. After HFS, can nerve block reduce postoperative} pain?

Postoperative pain is an undermanaged problem in older patients with hip fractures. It is challenging to control postoperative pain in patients who might have several comorbidities and are prone to cognitive decline [108]. Pain and fatigue are the major limiting factors that hinder early mobilization after HFS [109]. For pain relief, nerve blockade, spinal anesthesia, systemic analgesia, preoperative traction, multimodal pain management, neurostimulation, rehabilitation, and complementary and alternative medicine methods can be used. Among these modalities, there is moderate evidence for the effectiveness of nerve blocks [110]. Active pain control using a nerve block may reduce complications, such as delirium and length of hospital stay [108]. Paracetamol was used as a first-line drug for pain control; however, its effect is limited to severe pain. Nonsteroidal anti- inflammatory drugs (NSAIDs) are not recommended as hip fractures occur in old age, often accompanied by low kidney function and gastrointestinal erosion [17]. Opioids can cause adverse reactions such as confusion, nausea, and constipation. Regional anesthesia using a nerve block can be used for severe pain that is not controlled by paracetamol. Peripheral nerve block is also appropriate when adverse reactions associated with systemic medication use are of concern. It can effectively induce patients to participate in rehabilitation [111]. Femoral nerve and iliac fascia compartment blockades are the most commonly used methods [112].

In a randomized study of 141 patients with HFS aged $>70$ years, 71 patients received continuous femoral nerve block for 48 hours postoperatively, and 70 patients were administered intravenous morphine to maintain a verbal rating of $<5$ on a 10 -point scale. In the group that underwent continuous femoral nerve block surgery, cumulative rest pain was significantly improved on the 3rd and 30th days postoperatively as the secondary efficacy item (intervention group vs. standard care group, 2 vs. $5 ; \mathrm{p}=0.043$ ) [113]. In another randomized study of 161 patients aged $>60$ years, 79 patients were treated with continuous femoral nerve blocks using a catheter for 3 days postoperatively. The remaining 82 patients received conventional pain-relief therapy (intravenous analgesic therapy). On comparing pain, walking distance, and walking ability on the 3rd day after surgery, the group that received continuous nerve blocks showed significantly decreased pain and increased walking distance and ability on the 3rd day after surgery compared to the usual pain treatment [114]. Severe pain following hip fracture is a wellknown risk factor for delirium [115]. In a randomized, placebo-controlled study of 219 hip fracture patients aged $\geq 70$ years, 108 patients received continuous fascia iliaca compartment block until discharge or delirium occurrence, and the remaining 111 patients underwent the same procedure with placebo medication (physiological saline). The study was completed in 102 participants in the test group and 105 participants in the control group, and the incidence of delirium before and after surgery was significantly reduced in the group receiving continuous blockage-10.78\% (11/102) vs. $23.8 \%$ (25/105) [116].

By regional blockade, postoperative pain can be controlled without the use of opioids. However, the operator's technical skills and experience play a substan- 
tial role in the success or failure of a peripheral nerve block. Nerve blocks to control hip fracture pain require a certain skill level and tend to be less used [117]. Traditionally, when performing peripheral nerve blocks such as femoral nerve block, a technique performed by checking a body mark or an electrical neurostimulation technique has been used. Ultrasound guidance has been widely introduced in recent years. Under ultrasound imaging, vulnerable structures, such as blood vessels, can be avoided, and nerve blocks can be performed in a short period $[118,119]$. Compared to fluoroscopy, it can be easily performed without radiation exposure in outpatient clinics. An ultrasound-guided peripheral nerve block relies entirely on the skills and proficiency of the physicians to perform it; therefore, a well-organized training program is needed [120].

\section{Recommendation}

- Peripheral nerve blocks are suggested to relieve postoperative pain after HFS (evidence level: low [6 RCTs], grade of recommendation: weak).

\section{KQ11. After HFS, is VTE prevention using compression} therapy/drug treatment required?

VTE includes deep vein thrombosis (DVT) and pulmonary embolism (PE). VTE prevention is considered the standard care for patients with lower-extremity major orthopedic surgery [121]. In Asian countries, after major orthopedic surgeries (total knee arthroplasty, total hip arthroplasty, and HFS), the incidence of symptomatic VTE approximately one month after surgery is $1.5 \%$, which is lower than that in Western countries (4.3\%) without antithrombosis prevention treatment $[29,122]$. In Korea, the incidence of thrombosis for major orthopedic surgeries is $1.24 \%$ [123]. The incidence of VTE per 100,000 population for 5 years in the National Health Insurance data has increased from 8.83 in 2004 to 13.8 in 2008, especially among those aged $>60$ years [124]. Risk factors for VTE include advanced age, cancer, surgery, prolonged immobilization, fractures, paralysis, and oral contraceptives. Recent major surgeries are also known to be a significant risk factor [125]. HFS is a major surgery in orthopedic surgery, and when risk factors are combined, measures to prevent VTE are needed.

The Prevention of Venous Thromboembolism Guideline 2nd edition was published by the Korean Society of
Thrombosis and Hemostasis (KSTH), reflecting Korean VTE epidemiology in 2014, based on the 9th ACCP guideline [30]. The KSTH guidelines classified the risk of venous thrombosis into very low $(<0.5 \%)$, low $(0.5 \%-1.5 \%)$, moderate $(1.5 \%-3.0 \%)$, and high $(>3.0 \%)$ according to the incidence of symptomatic VTE. THA or HFS was considered moderate risk. If the patient had additional risk factors such as advanced age, a previous history of VTE, or thrombophilia, it was considered high risk [30]. Advanced age was not specified specifically in this guideline; however, in other studies of major orthopedic surgery, advanced age was defined as age $\geq 75$ years [126] or $\geq 90$ years [127].

In a systematic review update in 2017 by the AHRQ, the prevention of venous thrombosis after major orthopedic surgery (THR, TKR, and HFS) was stated as a standard of care. This review compared the superiority of thrombotic drugs and the effects of dose [121]. The main findings were that LMWH has a lower risk of pulmonary embolism, deep vein thrombosis, and bleeding than those with UHF. In the comparison between drugs and doses, there was a trade-off relationship between the prevention of VTE and the risk of bleeding.

In a randomized clinical trial of 80 patients who underwent surgery for a hip fracture over the age of 60 years, the incidence of DVT was significantly lower in the combination group of rivaroxaban and mechanical compression treatment than in the mechanical compression group 7-11 days after surgery (2.6\% vs. $19.5 \%)$ [128]. Another trial allocated 287 patients with HFS to the rivaroxaban alone group, LMWH alone group, and LMHW (1 week) and then rivaroxaban (after 1 week) combination groups for 2 weeks. When comparing the incidence, there was no difference in incidence between the three groups $(5.21 \%, 14.74 \%$, and $10.42 \%$, respectively, $\mathrm{p}=0.091)$ [129].

Considering the KSTH 2nd guideline and the above references, we recommend using pharmacological or mechanical prophylaxis for patients with HFS for at least 10-14 days. Recommended medications are lowmolecular-weight heparin (LMWH; 0.2-1 mg/kg SC daily), fondaparinux, low-dose unfractionated heparin (LDUH; 5,000 U SC every 8-12 hours), warfarin (dose adjust for PT [INR] of 1.5-2.5), or aspirin (100 mg PO daily). Mechanical prophylaxis can be applied using graduated compression stockings (pressure of $16-20 \mathrm{mmHg}$ ) and intermittent pneumatic compressions (repeated inflation 
of 11-12 seconds and deflation of 60 seconds). For patients with additional risk factors such as advanced age, general anesthesia, previous VTE, or cancer, pharmacological prophylaxis should be considered. Early ambulation was encouraged in all patients. Routine screening is not recommended for asymptomatic patients.

In accordance with the KSTH guidelines in 2014, active early ambulation and antithrombotic agents or mechanical compression are recommended because HFS is considered to be a moderate risk factor for VTE. If the patients are of advanced age or have a history of thrombosis and no risk of bleeding, antithrombotic agents are more strictly required. The cost-effectiveness of antithrombotic drugs and the risk of increased bleeding should be considered. First, active early ambulation and intermittent mechanical compressions are used, and insurance coverage criteria should be considered when using pharmacologic agents. The incidence of VTE after major orthopedic surgery varies according to race, possibly due to genetic and living environments, and studies on the natural history of asymptomatic VTE are required.

\section{Recommendation}

- After HFS, compression therapy/drug treatment is suggested to prevent venous thromboembolism (evidence level: 2 CPGs [acceptable], high [1 SR], low [2 RCTs], grade of recommendation: weak).

\section{KQ12. Should the indwelling catheter be removed early after HFS to reduce UTI?}

In a retrospective cohort study using US Medicare data $(n=35,904)$, when the catheterization method was maintained for more than 2 days after major surgery (coronary artery bypass and other chest cardiac operations, vascular surgery, general abdominal colorectal surgery, or hip or knee total joint arthroplasty), the risk of UTI was increased ( $R R=1.21)$ [130]. Maintaining an indwelling catheter after HFS may increase the risk of UTIs [131].

According to the 8.7 urinary catheterization section in the adapted CPG, catheterization should be avoided in general. However, in cases of urinary incontinence or urinary retention, and cardiac or renal function evaluation is required, the indwelling catheter can be maintained depending on the situation. It stated that fluid balance and pain management are necessary [19].

The incidence of infection did not differ between the clean intermittent catheterization (CIC) $(n=85)$ and urinary tract catheterization groups in patients who underwent HFS ( $9.4 \%$ vs. $11.8 \%, \mathrm{p}=0.618$ ). When normal bladder function was defined as $<150 \mathrm{~mL}$ of residual urine after natural urination, functional recovery was significantly fast in the CIC group ( 24 vs. 48 hours, $\mathrm{p}<0.001$ ) [132]. In another study, bladder function and UTI were compared on the 5th day after surgery. The incidence of UTI did not differ between the two groups ( $31 \%$ and $38 \%$ in groups 1 and 2, respectively). The recovery of urination was significantly fast in the CIC group (group 2) (37\% and $66 \%$, respectively; $\mathrm{p}<0.025$ ) [133]. In patients who underwent hip or knee replacement surgeries $(n=96)$, and maintained primary catheterization for 24 hours after surgery (group 1; 41 patients), UTIs did not occur more often during the 5 days after surgery than in those in the CIC group (group 2; 55 patients) (11\% and $15 \%$ in groups 1 and 2, respectively). In this study, when primary catheterization was maintained for 24 hours after surgery, the rate of urine retention ( $\geq 700 \mathrm{~mL}$ ) was significantly lower ( $7 \%$ and $45 \%$, respectively; $\mathrm{p}<0.01$ ) [134]. In the previous three trials comparing the occurrence of UTI between CIC and indwelling catheterization, the durations were all within 48 hours, and there was no difference in the risk of UTI during this period. Therefore, the results of these studies were limited to conditions within 48 hours after surgery.

Most hospitals are equipped with equipment to attempt natural urination after the early removal of the indwelling catheter and then to measure residual urine. Thus, this recommendation may not be difficult to apply in a clinical setting. The urination method after HFS should be decided considering the patient's physical function, nursing workforce, and equipment conditions.

\section{Recommendation}

- After HFS, the indwelling catheter is suggested to be removed as early as possible (evidence level: 1 CPG [acceptable], very low [3 RCTs], grade of recommendation: weak).

\section{KQ13. Can bisphosphonate administration reduce re-} fracture and mortality after HFS?

Fragility fractures, such as hip fractures, are a risk factor for fractures [135]. One of the causes of increased complications and related costs after hip fracture is a new 
osteoporotic fracture. Each year, 10.4 new fractures occur per 100 people with hip fractures, a 2.5 -fold increase compared to the case without hip fractures [136]. In one meta-analysis study, the risk ratio of refracture after hip fracture increased from 1.32 to approximately five times according to age [137]. In another meta-analysis study, fractures of the elbow, hip, and vertebrae in postmenopausal women increased the risk of refracture by approximately two times [138]. However, the rate of receiving osteoporosis treatment increased by only $3 \%$ after the occurrence of a hip fracture, suggesting that health care professionals showed a lack of interest in osteoporosis treatment even if a fracture occurred [139]. After fracture, less than $30 \%$ of women and less than $10 \%$ of men are receiving osteoporosis treatment. Osteoporosis treatment, such as bisphosphonate administration after fragility fracture, could reduce the incidence of refracture by $40 \%$ over 3 years [140]. In addition, the better the compliance with bisphosphonate, the lower the risk of refracture [141]. When a hip fracture occurs, considerable attention is needed for the diagnosis and treatment of osteoporosis [138]. Early initiation of bisphosphonate is recommended to reduce refractures after HFS, and fracture union is not adversely affected [142,143].

In one double-blinded RCT study, 2,127 patients aged $>50$ years who had a hip fracture were assigned to the zoledronic acid treatment group (1,065 patients) and the control group (1,062 patients) and compared refractures and mortality over 3 years. When received, refractures decreased by $35 \%$ and mortality by $28 \%$, and there was no difference in adverse reactions [143]. When zoledronic acid injection was administered when performing HFS (30 patients), compared to the non-injection group (30 patients), after follow-up for 1 year, the injection not only prevented new fractures, but also fracture pain, bone density, and life expectancy. The quality improved, and bone union was promoted [144]. In an RCT involving 220 hip joint patients aged $\geq 50$ years, taking alendronate 70 $\mathrm{mg}$ or risedronate $35 \mathrm{mg}$ weekly reduced the risk of death to $0.92 /$ month [145]. When the patients with HFS were randomized into the group that was administered alendronate weekly along with calcium+vitamin $\mathrm{D}$, and the control group that was administered calcium+vitamin D only, the mean difference in total hip BMD was $2.57 \%$, but there was no difference in mortality between the two groups at the 1 year follow-up [146]. In patients who underwent HFS, when risedronate was administered to prevent fracture of the other non-fractured side and observed for 3 years, the contralateral hip fracture was significantly reduced by $13.1 \%$ [147]. In a meta-analysis based on the above studies, bisphosphonate treatment after hip fracture reduced refracture and mortality [148]. Another meta-analysis evaluating the reduction of refracture and mortality of bisphosphonate after the incidence of fragile fractures, including hip fractures, also revealed that the OR of refracture was 0.499 and the OR of mortality was 0.662 [149].

When bisphosphonate is taken orally, the absorption rate in the intestine is low $(1 \%-5 \%)$. Therefore, taking it before meals in the morning is necessary to maximize absorption in the body and to avoid interfering with the absorption of the drug, but this may be inconvenient. In addition, to reduce the possibility of esophageal irritation, the patient should swallow with a sufficient amount of water ( $200 \mathrm{~mL}$ or more) and should not lie down for about 1 hour after taking it. There is a risk of adverse esophageal reactions if the patient does not take it according to the instructions. If the patient has reflux esophagitis or esophageal disease, intravenous administration may be an alternative. In addition, when this drug is used for the first time, flu-like symptoms such as body aches may occur, and acetaminophen or nonsteroidal anti-inflammatory drugs may be administered for 3 or 4 days to prevent or treat these symptoms. Since bisphosphonate may affect renal function, it should not be administered to patients with severe renal failure with a creatinine clearance of $30-35 \mathrm{~mL} / \mathrm{min}$ or less. In addition, the risk of jaw bone necrosis increases when bisphosphonate is used for a long time, and an association with atypical femur fractures has been reported. For more information on this, refer to the "Guidelines for Diagnosis and Treatment of Osteoporosis" published by the Korean Bone Metabolism Society [150]. In Korea, in order to use bisphosphonates in clinical settings, it is necessary to fulfill the reimbursement criteria of bone densitometry for insurance coverage. As a treatment for osteoporosis, in addition to bisphosphonates, parathyroid hormone and denosumab (RANKL inhibitor) are also widely used, so studies on the effects of these agents on refracture and mortality after hip fracture are needed.

Recommendation 
- After HFS, bisphosphonate administration is suggested to reduce refracture and mortality (evidence level: low [2 SRs], grade of recommendation grade: weak).

KQ14. After HFS, does nutritional evaluation and planning help functional recovery?

Along with rehabilitation exercises, nutrition is also important for the recovery of patients with hip fractures [151]. Malnutrition, which can be determined using a nutritional assessment tool, is not only a factor that increases the risk of fracture [152], but also results in increase in mortality and complications after fracture $[153,154]$.

In particular, malnutrition is common in older patients with hip fractures, which negatively affects the recovery of function after fracture, and is associated with increased postoperative complication rates and rehabilitation period, delayed wound recovery, poor QoL, and increased medical costs [155-157]. Planning and implementation of nutritional intervention, including nutritional counseling and provision of food for patients, as well as determination of malnutrition using appropriate nutritional evaluation tools, are cost-effective and result in improved nutritional status and functional recovery in older patients with hip fractures [155].

For 86 patients hospitalized for hip fracture, the nutritional status evaluated using the Mini Nutritional Assessment (MNA)-18 item within 72 hours after hospitalization was gait impairment $(\mathrm{OR}=0.773, \mathrm{p}=0.001)$ and mortality at 6 months after fracture $(\mathrm{HR}=0.869, \mathrm{p}=0.04)$, and as the MNA score increased by one point, the proportion of normal walking increased by $29 \%$ and the mortality rate decreased by $15 \%$ [154]. In a systematic review of the literature that analyzed the effect of nutritional status and nutritional intervention on the prognosis of older patients with hip fractures (44 studies; 26,281 target patients), MNA was an independent indicator predicting functional recovery after discharge, and malnutrition was associated with delayed functional recovery and increased incidence and mortality of complications such as delirium, sepsis, and pressure sores after surgery. Nutritional intervention in providing food for patients affected increased caloric and protein intake during hospitalization, increased protein intake, decreased bed sores and incidence period, and increased muscle mass. In addition, multidisciplinary nutrition intervention including a dietitian led to decreased incidence of malnutrition and mortality and improved QoL (EuroQol-5D scale), $\mathrm{ADL}$, and gait recovery [155]. In a non-randomized controlled study involving 124 hip fracture patients 50 years of age or older, when comparing nutritional intake after surgery $(n=64)$ with normal treatment alone $(n=60)$, the group who were trained for intake under a nutrition plan showed increased milk intake and sun exposure time, and decreased mortality rate for one year after surgery compared to the control group [158].

Malnutrition in patients with hip fractures is an adjustable risk factor that can predict future mortality and complications. If nutritional assessment is performed using appropriate nutritional evaluation tools, patients with a high risk of malnutrition after HFS can be found. Nutritional intervention conducted by a multidisciplinary team, including clinical nutritionists, is expected to improve the nutritional status of patients and recover their function. Currently, in Korea, nutritional status evaluation and nutritional intervention after hip surgery are not yet covered by the National Health Insurance, and nutritional management of patients after hip surgery is rarely performed under the prescription of physicians. Therefore, it is necessary to increase the interest and recognition of health care professionals on the nutritional status of patients, and to apply this, the resources and human power of each hospital should be prepared. In addition, it is necessary to develop assessment guidelines for the nutritional status of patients with HFS and to develop a standardized nutrition management program for patients undergoing hip surgery.

\section{Recommendation}

- After HFS, nutritional evaluation and planning are suggested for functional recovery (evidence level: low [1 SR], low [2 RCTs], very low [1 non-RCT], grade of recommendation: weak).

\section{KQ15. After HFS, does high protein supplementation} help restore function?

To maintain muscle mass and strength and to prevent senility, adequate protein intake is an essential nutritional factor to be considered [159]. According to the World Health Organization (WHO), consuming $0.8 \mathrm{~g}$ of protein per $\mathrm{kg}$ of body weight per day in older adults can improve sarcopenia along with exercise $[160,161]$. In older adults over 65, 1.0-1.2 $\mathrm{g}$ of protein per $\mathrm{kg}$ is recommended [162]. 
In a systematic review of the effects (benefits and harms) of starting nutritional treatment within one month after the onset of hip fracture in patients aged $\geq 65$ years, as comparing the effects of high protein and protein-free nutrition, there was no difference in the mortality rate among the groups (30/181 vs. $21 / 180 ; 95 \% \mathrm{CI}, 0.82-2.37$ ) [163]. High protein supply ( $20 \mathrm{~g}$ of protein for 60 days [164]) and $20.4 \mathrm{~g}$ of protein for 17 weeks [165] decreased unfavorable outcomes (66/113 vs. 82/110; RR=0.78; $95 \%$, CI 0.65-0.95) in studies investigating mortality or complications following hip fracture [163]. In a randomized study of 32 patients who underwent HFS, functional outcomes were compared between group A, who consumed $4 \mathrm{~g}$ of amino acids daily for 2 months $(\mathrm{n}=16)$ and group $B$ without $(n=16)$ before and after intervention. Ten patients with sarcopenia in group A showed significant improvement in hand grip strength, Timed Up and Go, and the Iowa Level of Assistance (ILOA). In contrast, 12 patients with sarcopenia in group B showed significant improvement only in the ILOA [151]. The group that consumed $8 \mathrm{~g}$ of amino acids daily (RE group, rehab+amino acid; $\mathrm{n}=28$ ), placebo group (RP group, rehab+amino acid placebo; $n=28$ ), and rehabilitation-only groups (Rehab; $\mathrm{n}=27$ ) were randomly assigned to 83 patients, on average, 20 days after HFS. In the RE group, the 6 -minute walking distance was significantly improved $(\mathrm{p}=0.04)$ compared to the other two groups (RP and Rehab group) (RE group +118.2 vs. RP group +73.6, Rehab group +65.4) [166]. In 152 older patients who underwent HFS, the group with $40 \mathrm{~g}$ of protein daily taken for 3 months $(\mathrm{n}=73)$ was compared with normal nutritional management only $(n=79)$ for up to 5 years. At three months, the nutritional status further improved, but there was no difference in hospital stay, refracture, or mortality [167]. One randomized controlled study regarding the short-term postoperative effects after high protein intake was conducted on 38 patients over 60 years of age who underwent HFS. The study was divided into 20 patients receiving 32.3 g protein daily for 1-2 weeks after surgery, and undergoing rehabilitation treatment, and 18 patients receiving only rehabilitation treatment for 2 weeks postoperatively. The proteintaking group had higher knee joint extension strength ( $0.5 \mathrm{Nm} / \mathrm{kg}$ vs. $0.33 \mathrm{Nm} / \mathrm{kg}$, assessed by isokinetic knee extension) and higher scores of Modified Barthel Index than the other group [168]. When nutrition containing 36 $\mathrm{g}$ of protein was taken additionally for $\mathbf{3 0}$ days after sur- gery, it was also helpful for wound healing and muscle strength improvement [169].

A high-protein diet can help reduce complications and improve muscle strength. High-protein diets are not recommended for patients with proteinuria or decreased renal function. In addition, if the patient suffers from gout, it is better to intake protein from eggs, dairy products, beans, and legumes rather than fish, shellfish, or meat. Although the number of hip fracture patients continues to increase in older adults, the protein intake of older Korean adults is very low in quantity and quality. In particular, protein supplements should be considered along with nutrition education for high-protein meals in older patients with limited digestive function.

\section{Recommendation}

- After HFS, it is suggested to provide high protein supplementation for functional recovery (evidence level: low [1 SR], very low [5 RCTs], grade of recommendation: weak).

\section{DISCUSSION}

We developed a CPG based on evidence from the literature regarding rehabilitation issues for patients with hip fractures. This guideline covers the structures and clinical settings of fracture rehabilitation, the effectiveness of rehabilitative treatments, and the management of combined problems after HFS. As this CPG has focused on rehabilitation issues after fragility HFS, topics related to the diagnosis, surgical techniques, pathologic fractures, and pediatric fractures were not included in the developmental process. As for rehabilitation structures and settings, a multidisciplinary approach is strongly recommended based on the level of evidence and expert opinion. Starting rehabilitation early and community- or home-based rehabilitation is recommended weakly concerning relative benefit and a low level of evidence. Among the rehabilitative treatments, progressive muscle strengthening and balance exercises and ADL training are strongly recommended, while weight-bearing exercises are weakly recommended due to the relatively low level of evidence and potential risk of excessive weight loading. To manage the combined problems after HFS, we proposed a nerve block for pain relief, compression treatment/medications to prevent VTE, early removal of indwelling catheter, 
bisphosphonate administration to reduce refracture rate and mortality, and nutritional planning/intervention for functional recovery with a weak recommendation. This is a Korean CPG based on the level of evidence and domestic acceptance and applicability, as well as experts' consensus on the overall issues covering the rehabilitation required for hip fracture patients.

Multidisciplinary care with early mobilization has been emphasized in most of the previous guidelines $[22,170,171]$. However, the incremental benefit of multidisciplinary interventions, over and above usual care, may be difficult to ascertain in clinical trials [170]. In our guideline, we included four systematic reviews with a medium level of evidence when the risk of bias was evaluated using AMSTAR 2.0. Despite discrepant results in mortality, length of stay, and cost-effectiveness, overall findings supported better ADL and mobility outcomes following multidisciplinary interventions compared to usual care. Therefore, the panel could make a strong recommendation for multidisciplinary rehabilitation in patients with HFS, with sufficient evidence to improve functional outcomes.

Active physiotherapy and structural exercises are critical for hip fracture recovery. Among these interventions, strengthening and balance training have been recommended with moderate to high quality of evidence in most clinical guidelines $[17,22,170,171]$, although weightbearing exercises have been argued in terms of timing and progression depending on surgical type, even though the benefit of treatment is expected to be high. One systematic review reported that arthroplasty provided superior functional outcomes due to earlier weight-bearing than internal fixation in older patients with hip fractures [172]. In a recent CPG from the American Physical Therapy Association, weight-bearing exercise was recommended as a multicomponent structural exercise [24]. We suggest that weight-bearing exercise is recommended after HFS, but close communication between surgeons and rehabilitation physicians is required to determine the timing and level of weight-bearing exercises.

A greater proportion of hip fracture patients are unable to maintain or regain their mobility and functional abilities after discharge from inpatient rehabilitation. Therefore, there is a vital need for community-based rehabilitation services, including home-based care, to maintain the progress gained from inpatient care after discharge. To date, a variety of home-based rehabilitation models have been implemented, depending on the provision of locally available services. "Early Supported Discharge" (ESD) or "Intermediate Care" at home are some community-based rehabilitation programs [17]. The NICE guidelines recommend ESD at home as part of a hip fracture program, provided that the multidisciplinary rehabilitation team remains involved, and the patient has not yet achieved full rehabilitation potential [17]. In our guidelines, we investigated the evidence for the homebased rehabilitation program separately in the setting of the recovery phase following the acute phase and chronic maintenance phase. If there is a difference in the level of evidence for each setting, specific recommendations should be made accordingly. However, in the current systematic review of the literature, the level of evidence was not high for both, so we made weak recommendations for both.

Our guidelines had some limitations. Because of the limited time and budget for the development of CPG, some clinical questions related to rehabilitation issues were not included in the current developmental process. For example, the examination and assessment of impairment and activity limitations were not included in this guideline. The use of standardized "outcome measures" is critical to determine which intervention is effective. Recently, a hip fracture core outcome set was developed and recommended for use in clinical trials [173,174]. It is necessary to cover the clinical questions more comprehensively, including assessment issues in the next update or revision of the guidelines. Second, the current recommendations were made by an expert panel based on domestic acceptance and applicability considering the healthcare system and resources in Korea. Nonetheless, the level of evidence for each clinical question was determined mainly based on the results of studies conducted in other countries. High-quality domestic studies related to fracture rehabilitation should be conducted in the future. Third, the survey data on patients' preferences were referred to in the guideline development, but these data did not seem to be directly reflected in clinical question formation. Patient and public involvement have been recognized as key components of guideline development [175]. Further research is needed to determine how patient and public involvement are effectively engaged in guideline development and implementation. 
This CPG is the first guideline that reflects the level of evidence of relevant literature and the consensus of multidisciplinary experts, and faithfully follows the methodology of CPG development, focusing on rehabilitation after HFS. It is expected to be widely used in a variety of fields, including physicians and other healthcare professionals in a primary to a tertiary center, as well as patients and caregivers.

\section{CONFLICT OF INTEREST}

No potential conflict of interest relevant to this article was reported.

\section{ACKNOWLEDGMENTS}

The development of the guideline was supported by the Korean Academy of Rehabilitation Medicine and Korean Academy of Geriatric Rehabilitation Medicine.

We would like to express our sincere gratitude to external reviewers and advisors for CPG methodology: Woong $\mathrm{Ju}, \mathrm{MD}, \mathrm{PhD}$ (Department of Obstetrics and Gynecology, Ewha Womans University, Korea); Yong-Chan Ha, MD, PhD (Department of Orthopaedic Surgery, ChungAng University College of Medicine, Korea); Chul Kim, MD, PhD (Department of Rehabilitation Medicine, Inje University School of Medicine, Sanggye Paik Hospital, Korea); Soo Young Kim, MD, PhD (Department of Family Medicine, Kangdong Sacred Heart Hospital, Hallym University College of Medicine, Korea); Doyeun Oh, MD, PhD (Department of Internal Medicine, CHA Bundang Medical Center, CHA University School of Medicine, Korea); Kyoung Ha Park (ONES Global); Si-Bog Park, MD, $\mathrm{PhD}$ (Department of Rehabilitation Medicine, Hanyang University College of Medicine, Korea); and Jong Lull Yoon, MD, PhD (Department of Family Medicine, Hallym University Dongtan Sacred Heart Hospital, Korea).

\section{SUPPLEMENTARY MATERIALS}

Supplementary materials can be found via http://doi. org/10.5535/arm.21110.

\section{REFERENCES}

1. Lee YK, Kim JW, Lee MH, Moon KH, Koo KH. Trend in the age-adjusted incidence of hip fractures in South Korea: systematic review. Clin Orthop Surg 2017;9:420-3.

2. Gullberg B, Johnell O, Kanis JA. World-wide projections for hip fracture. Osteoporos Int 1997;7:407-13.

3. Kang HY, Yang KH, Kim YN, Moon SH, Choi WJ, Kang DR, et al. Incidence and mortality of hip fracture among the elderly population in South Korea: a population-based study using the national health insurance claims data. BMC Public Health 2010;10:230.

4. Zuckerman JD. Hip fracture. N Engl J Med 1996;334:1519-25.

5. Mears SC. Classification and surgical approaches to hip fractures for nonsurgeons. Clin Geriatr Med 2014;30:229-41.

6. Fox KM, Magaziner J, Hebel JR, Kenzora JE, Kashner TM. Intertrochanteric versus femoral neck hip fractures: differential characteristics, treatment, and sequelae. J Gerontol A Biol Sci Med Sci 1999;54:M63540.

7. Kanis JA, Johnell O. The burden of osteoporosis. J Endocrinol Invest 1999;22:583-8.

8. Nikitovic M, Wodchis WP, Krahn MD, Cadarette SM. Direct health-care costs attributed to hip fractures among seniors: a matched cohort study. Osteoporos Int 2013;24:659-69.

9. Nightingale EJ, Sturnieks D, Sherrington C, Moseley AM, Cameron ID, Lord SR. Impaired weight transfer persists at least four months after hip fracture and rehabilitation. Clin Rehabil 2010;24:565-73.

10. Braithwaite RS, Col NF, Wong JB. Estimating hip fracture morbidity, mortality and costs. J Am Geriatr Soc 2003;51:364-70.

11. Magaziner J, Lydick E, Hawkes W, Fox KM, Zimmerman SI, Epstein RS, et al. Excess mortality attributable to hip fracture in white women aged 70 years and older. Am J Public Health 1997;87:1630-6.

12. Tedesco D, Gibertoni D, Rucci P, Hernandez-Boussard T, Rosa S, Bianciardi L, et al. Impact of rehabilitation on mortality and readmissions after surgery for hip fracture. BMC Health Serv Res 2018;18:701.

13. Foss NB, Kehlet H. Mortality analysis in hip fracture patients: implications for design of future outcome trials. Br J Anaesth 2005;94:24-9.

14. Cheng SY, Levy AR, Lefaivre KA, Guy P, Kuramoto L, Sobolev B. Geographic trends in incidence of hip 
fractures: a comprehensive literature review. Osteoporos Int 2011;22:2575-86.

15. Burge R, Dawson-Hughes B, Solomon DH, Wong JB, King A, Tosteson A. Incidence and economic burden of osteoporosis-related fractures in the United States, 2005-2025. J Bone Miner Res 2007;22:465-75.

16. Chudyk AM, Jutai JW, Petrella RJ, Speechley M. Systematic review of hip fracture rehabilitation practices in the elderly. Arch Phys Med Rehabil 2009;90:24662.

17. National Institute for Health and Care Excellence. Hip fracture: management 2017 [Internet]. London, UK: National Institute for Health and Care Excellence; c2021 [cited 2021 May 24]. Available from: https://www.nice.org.uk/guidance/cg124.

18. British Orthopaedic Association. The care of patients with fragility fracture [Internet]. London, UK: British Orthopaedic Association; 2007 [cited 2021 May 24]. Available from: https://www.bgs.org.uk/ sites/default/files/content/attachment/2018-05-02/ Blue\%20Book\%20on\%20fragility\%20fracture\%20 care.pdf.

19. Scottish Intercollegiate Guidelines Network. Management of hip fracture in older people: a national clinical guideline [Internet]. Edinburgh, Scotland: Scottish Intercollegiate Guidelines Network; 2009 [cited 2021 May 24]. Available from: https://pdf4pro. $\mathrm{com} / \mathrm{cdn} /$ part-of-nhs-quality-improvement-scotland-2531e4.pdf.

20. Scottish Committee for Orthopaedics and Trauma, Royal College of Emergency Medicine National Board for Scotland, British Geriatrics Society. Scottish Standards of care for hip fracture patients 2018 [Internet]. Edinburgh, Scotland: NHS Scotland; c2019 [cited 2021 May 24]. Available from: https:// www.shfa.scot.nhs.uk/_docs/2018/Scottish-standards-of-care-for-hip-fracture-patients-2018.pdf.

21. Australian and New Zealand Hip Fracture Registry. Australian and New Zealand Guideline for hip fracture care [Internet]. Sydney: Australian and New Zealand Hip Fracture Registry Steering Group; 2014 [cited 2021 May 24]. Available from: https://anzhfr. org/wp-content/uploads/2016/07/ANZ-Guidelinefor-Hip-Fracture-Care.pdf.

22. Mak JC, Cameron ID, March LM; National Health and Medical Research Council. Evidence-based guidelines for the management of hip fractures in older persons: an update. Med J Aust 2010;192:3741.

23. Agency for Healthcare Research and Quality. Treatment of common hip fractures (AHRQ Publication No. 09-E013) [Internet]. Rockville, MD: Agency for Healthcare Research and Quality; 2009 [cited 2021 May 24]. Available from: https://www.ahrq.gov/ downloads/pub/evidence/pdf/hipfracture/hipfracture.pdf.

24. McDonough CM, Harris-Hayes M, Kristensen MT, Overgaard JA, Herring TB, Kenny AM, et al. Physical therapy management of older adults with hip fracture. J Orthop Sports Phys Ther 2021;51:CPG1-81.

25. Yoo JI, Lee YK, Koo KH, Park YJ, Ha YC. Concerns for older adult patients with acute hip fracture. Yonsei Med J 2018;59:1240-4.

26. Saltvedt I, Prestmo A, Einarsen E, Johnsen LG, Helbostad JL, Sletvold O. Development and delivery of patient treatment in the Trondheim Hip Fracture Trial: a new geriatric in-hospital pathway for elderly patients with hip fracture. BMC Res Notes 2012;5:355.

27. Hutchings L, Fox R, Chesser T. Proximal femoral fractures in the elderly: how are we measuring outcome? Injury 2011;42:1205-13.

28. Scottish Intercollegiate Guidelines Network. Risk reduction and management of delirium: a national clinical guideline. Edinburgh, Scotland: Scottish Intercollegiate Guidelines Network; 2019.

29. Falck-Ytter Y, Francis CW, Johanson NA, Curley C, Dahl OE, Schulman S, et al. Prevention of VTE in orthopedic surgery patients: Antithrombotic Therapy and Prevention of Thrombosis, 9th ed. American College of Chest Physicians Evidence-Based Clinical Practice Guidelines. Chest 2012;141(2 Suppl):e278S325S.

30. Bang SM, Jang MJ, Kim KH, Yhim HY, Kim YK, Nam $\mathrm{SH}$, et al. Prevention of venous thromboembolism, 2nd edition: Korean Society of Thrombosis and Hemostasis Evidence-based Clinical Practice Guidelines. J Korean Med Sci 2014;29:164-71.

31. Kim SY, Park JE, Lee YJ, Seo HJ, Sheen SS, Hahn S, et al. Testing a tool for assessing the risk of bias for nonrandomized studies showed moderate reliability and promising validity. J Clin Epidemiol 2013;66:408-14. 
32. Higgins JP, Thomas J. Cochrane handbook for systematic reviews of interventions. London, UK: Cochrane Collaboration; 2021.

33. Shea BJ, Reeves BC, Wells G, Thuku M, Hamel C, Moran J, et al. AMSTAR 2: a critical appraisal tool for systematic reviews that include randomised or nonrandomised studies of healthcare interventions, or both. BMJ 2017;358:j4008.

34. The Grading of Recommendations Assessment, Development and Evaluation (GRADE) working group [Internet]. London, UK: The GRADE Working Group; c2021 [cited 2021 May 24]. Available from: www. gradeworkinggroup.org.

35. Murad MH, Montori VM, Ioannidis JP, Jaeschke R, Devereaux PJ, Prasad K, et al. How to read a systematic review and meta-analysis and apply the results to patient care: users' guides to the medical literature. JAMA 2014;312:171-9.

36. Pollock A, Farmer SE, Brady MC, Langhorne P, Mead GE, Mehrholz J, et al. An algorithm was developed to assign GRADE levels of evidence to comparisons within systematic reviews. J Clin Epidemiol 2016;70:106-10.

37. Oh MK, Jo H, Lee YK. Improving the reliability of clinical practice guideline appraisals: effects of the Korean AGREE II scoring guide. J Korean Med Sci 2014;29:771-5.

38. Farrow L, Hall A, Wood AD, Smith R, James K, Holt G, et al. Quality of care in hip fracture patients: the relationship between adherence to national standards and improved outcomes. J Bone Joint Surg Am 2018;100:751-7.

39. Bonanni S, Sorensen AA, Dubin J, Drees B. The role of the fracture liaison service in osteoporosis care. Mo Med 2017;114:295-8.

40. McLellan AR, Gallacher SJ, Fraser M, McQuillian C. The fracture liaison service: success of a program for the evaluation and management of patients with osteoporotic fracture. Osteoporos Int 2003;14:1028-34.

41. Dreinhofer KE, Mitchell PJ, Begue T, Cooper C, Costa ML, Falaschi P, et al. A global call to action to improve the care of people with fragility fractures. Injury 2018;49:1393-7.

42. Adunsky A, Levenkrohn S, Fleissig Y, Arad M, Heruti RJ. Rehabilitation outcomes in patients with full weight-bearing hip fractures. Arch Gerontol Geriatr
2001;33:123-31.

43. Flikweert ER, Wendt KW, Diercks RL, Izaks GJ, Landsheer D, Stevens M, et al. Complications after hip fracture surgery: are they preventable? Eur J Trauma Emerg Surg 2018;44:573-80.

44. Adunsky A, Arad M, Levi R, Blankstein A, Zeilig G, Mizrachi E. Five-year experience with the 'Sheba' model of comprehensive orthogeriatric care for elderly hip fracture patients. Disabil Rehabil 2005;27:1123-7.

45. Pioli G, Bendini C, Pignedoli P, Giusti A, Marsh D. Orthogeriatric co-management: managing frailty as well as fragility. Injury 2018;49:1398-402.

46. Thingstad P, Taraldsen K, Saltvedt I, Sletvold O, Vereijken B, Lamb SE, et al. The long-term effect of comprehensive geriatric care on gait after hip fracture: the Trondheim Hip Fracture Trial: a randomised controlled trial. Osteoporos Int 2016;27:933-42.

47. Kammerlander C, Roth T, Friedman SM, Suhm N, Luger TJ, Kammerlander-Knauer U, et al. Ortho-geriatric service: a literature review comparing different models. Osteoporos Int 2010;21(Suppl 4):S63746.

48. Giusti A, Barone A, Razzano M, Pizzonia M, Pioli G. Optimal setting and care organization in the management of older adults with hip fracture. Eur J Phys Rehabil Med 2011;47:281-96.

49. Nordstrom P, Thorngren KG, Hommel A, Ziden L, Anttila S. Effects of geriatric team rehabilitation after hip fracture: meta-analysis of randomized controlled trials. J Am Med Dir Assoc 2018;19:840-5.

50. Bachmann S, Finger C, Huss A, Egger M, Stuck AE, Clough-Gorr KM. Inpatient rehabilitation specifically designed for geriatric patients: systematic review and meta-analysis of randomised controlled trials. BMJ 2010;340:c1718.

51. Halbert J, Crotty M, Whitehead C, Cameron I, Kurrle S, Graham S, et al. Multi-disciplinary rehabilitation after hip fracture is associated with improved outcome: a systematic review. J Rehabil Med 2007;39:507-12.

52. Handoll HH, Cameron ID, Mak JC, Finnegan TP. Multidisciplinary rehabilitation for older people with hip fractures. Cochrane Database Syst Rev 2009;(4):CD007125.

53. Chilov MN, Cameron ID, March LM; Australian 
National Health and Medical Research Council. Evidence-based guidelines for fixing broken hips: an update. Med J Aust 2003;179:489-93.

54. Oldmeadow LB, Edwards ER, Kimmel LA, Kipen E, Robertson VJ, Bailey MJ. No rest for the wounded: early ambulation after hip surgery accelerates recovery. ANZ J Surg 2006;76:607-11.

55. Su B, Newson R, Soljak H, Soljak M. Associations between post-operative rehabilitation of hip fracture and outcomes: national database analysis (90 characters). BMC Musculoskelet Disord 2018;19:211.

56. Frenkel Rutenberg T, Vitenberg M, Haviv B, Velkes S. Timing of physiotherapy following fragility hip fracture: delays cost lives. Arch Orthop Trauma Surg 2018;138:1519-24.

57. Kuru T, Olcar HA. Effects of early mobilization and weight bearing on postoperative walking ability and pain in geriatric patients operated due to hip fracture: a retrospective analysis. Turk J Med Sci 2020;50:117-25.

58. Pioli G, Frondini C, Lauretani F, Davoli ML, Pellicciotti F, Martini E, et al. Time to surgery and rehabilitation resources affect outcomes in orthogeriatric units. Arch Gerontol Geriatr 2012;55:316-22.

59. Kamel HK, Iqbal MA, Mogallapu R, Maas D, Hoffmann RG. Time to ambulation after hip fracture surgery: relation to hospitalization outcomes. J Gerontol A Biol Sci Med Sci 2003;58:1042-5.

60. Taylor NF, Dodd KJ, Damiano DL. Progressive resistance exercise in physical therapy: a summary of systematic reviews. Phys Ther 2005;85:1208-23.

61. Aarden JJ, van der Schaaf $M$, van der Esch $M$, Reichardt LA, van Seben R, Bosch JA, et al. Muscle strength is longitudinally associated with mobility among older adults after acute hospitalization: the Hospital-ADL study. PLoS One 2019;14:e0219041.

62. Roy MA, Doherty TJ. Reliability of hand-held dynamometry in assessment of knee extensor strength after hip fracture. Am J Phys Med Rehabil 2004;83:8138.

63. Delorme TL, Watkins AL. Technics of progressive resistance exercise. Arch Phys Med Rehabil 1948;29:263-73.

64. Deschenes MR. General principles of exercise prescription. In: Riebe D, editor. ACSM's Guidelines for Exercise Testing and Prescription. 10th ed. Philadel- phia, PA: Wolters Kluwer; 2018. p. 143-74.

65. Lee SY, Yoon BH, Beom J, Ha YC, Lim JY. Effect of lower-limb progressive resistance exercise after hip fracture surgery: a systematic review and meta-analysis of randomized controlled studies. J Am Med Dir Assoc 2017;18:1096.e19-1096.e26.

66. Stasi S, Papathanasiou G, Chronopoulos E, Dontas IA, Baltopoulos IP, Papaioannou NA. The effect of intensive abductor strengthening on postoperative muscle efficiency and functional ability of hip-fractured patients: a randomized controlled trial. Indian J Orthop 2019;53:407-19.

67. Kronborg L, Bandholm T, Palm H, Kehlet H, Kristensen MT. Effectiveness of acute in-hospital physiotherapy with knee-extension strength training in reducing strength deficits in patients with a hip fracture: a randomised controlled trial. PLoS One 2017;12:e0179867.

68. Koval KJ, Sala DA, Kummer FJ, Zuckerman JD. Postoperative weight-bearing after a fracture of the femoral neck or an intertrochanteric fracture. J Bone Joint Surg Am 1998;80:352-6.

69. Wu J, Kurrle S, Cameron ID. Restricted weight bearing after hip fracture surgery in the elderly: economic costs and health outcomes. J Eval Clin Pract 2009;15:217-9.

70. Koval KJ, Friend KD, Aharonoff GB, Zukerman JD. Weight bearing after hip fracture: a prospective series of 596 geriatric hip fracture patients. J Orthop Trauma 1996;10:526-30.

71. Bhandari M, Swiontkowski M. Management of acute hip fracture. N Engl J Med 2017;377:2053-62.

72. Warren J, Sundaram K, Anis H, McLaughlin J, Patterson B, Higuera CA, et al. The association between weight-bearing status and early complications in hip fractures. Eur J Orthop Surg Traumatol 2019;29:141927.

73. Ottesen TD, McLynn RP, Galivanche AR, Bagi PS, Zogg CK, Rubin LE, et al. Increased complications in geriatric patients with a fracture of the hip whose postoperative weight-bearing is restricted: an analysis of 4918 patients. Bone Joint J 2018;100B:1377-84.

74. Pfeufer D, Zeller A, Mehaffey S, Bocker W, Kammerlander C, Neuerburg C. Weight-bearing restrictions reduce postoperative mobility in elderly hip fracture patients. Arch Orthop Trauma Surg 2019;139:1253-9. 
75. Voeten SC, Nijmeijer WS, Vermeer M, Schipper IB, Hegeman JH; DHFA Taskforce study group. Validation of the Fracture Mobility Score against the Parker Mobility Score in hip fracture patients. Injury 2020;51:395-9.

76. Ariza-Vega P, Jimenez-Moleon JJ, Kristensen MT. Non-weight-bearing status compromises the functional level up to $1 \mathrm{yr}$ after hip fracture surgery. Am J Phys Med Rehabil 2014;93:641-8.

77. Siebens HC, Sharkey P, Aronow HU, Horn SD, Munin $\mathrm{MC}$, DeJong G, et al. Outcomes and weight-bearing status during rehabilitation after arthroplasty for hip fractures. PM R 2012;4:548-55.

78. Sherrington C, Lord SR, Herbert RD. A randomized controlled trial of weight-bearing versus non-weightbearing exercise for improving physical ability after usual care for hip fracture. Arch Phys Med Rehabil 2004;85:710-6.

79. Harkess JW, Crockarell JR. Arthroplasty of the hip. In: Azar FM, Beaty JH, Canale ST, editors. Campbell's operative orthopaedics. 13th ed. Philadelphia, PA: Elsevier; 2017. p. 2817-64.

80. Carlin L, Sibley K, Jenkinson R, Kontos P, McGlasson $\mathrm{R}$, Kreder HJ, et al. Exploring Canadian surgeons' decisions about postoperative weight bearing for their hip fracture patients. J Eval Clin Pract 2018;24:42-7.

81. Robbins AS, Rubenstein LZ, Josephson KR, Schulman BL, Osterweil D, Fine G. Predictors of falls among elderly people: results of two populationbased studies. Arch Intern Med 1989;149:1628-33.

82. Lee SY, Jung SH, Lee SU, Ha YC, Lim JY. Effect of balance training after hip fracture surgery: a systematic review and meta-analysis of randomized controlled studies. J Gerontol A Biol Sci Med Sci 2019;74:167985.

83. Wu JQ, Mao LB, Wu J. Efficacy of balance training for hip fracture patients: a meta-analysis of randomized controlled trials. J Orthop Surg Res 2019;14:83.

84. Martin-Martin LM, Valenza-Demet G, JimenezMoleon JJ, Cabrera-Martos I, Revelles-Moyano FJ, Valenza MC. Effect of occupational therapy on functional and emotional outcomes after hip fracture treatment: a randomized controlled trial. Clin Rehabil 2014;28:541-51.

85. Uruma M, Momosaki R, Chono M, Fukumoto M, Watanabe T, Nakamura M, et al. Effectiveness of acute in-hospital occupational therapy for older patients with hip fracture. Geriatr Gerontol Int 2019;19:611-5.

86. Lee SY, Jung SH, Lee SU, Ha YC, Lim JY. Is occupational therapy after hip fracture surgery effective in improving function? A systematic review and metaanalysis of randomized controlled studies. Am J Phys Med Rehabil 2019;98:292-8.

87. Heinrich S, Rapp K, Rissmann U, Becker C, Konig $\mathrm{HH}$. Cost of falls in old age: a systematic review. Osteoporos Int 2010;21:891-902.

88. Prestmo A, Hagen G, Sletvold O, Helbostad JL, Thingstad P, Taraldsen K, et al. Comprehensive geriatric care for patients with hip fractures: a prospective, randomised, controlled trial. Lancet 2015;385:1623-33.

89. Milte R, Miller MD, Crotty M, Mackintosh S, Thomas $S$, Cameron ID, et al. Cost-effectiveness of individualized nutrition and exercise therapy for rehabilitation following hip fracture. J Rehabil Med 2016;48:378-85.

90. Lahtinen A, Leppilahti J, Vahanikkila H, Harmainen S, Koistinen P, Rissanen P, et al. Costs after hip fracture in independently living patients: a randomised comparison of three rehabilitation modalities. Clin Rehabil 2017;31:672-85.

91. Dyer SM, Crotty M, Fairhall N, Magaziner J, Beaupre LA, Cameron ID, et al. A critical review of the longterm disability outcomes following hip fracture. BMC Geriatr 2016;16:158.

92. Mathew RO, Hsu WH, Young Y. Effect of comorbidity on functional recovery after hip fracture in the elderly. Am J Phys Med Rehabil 2013;92:686-96.

93. Stott DJ, Handoll HH. Rehabilitation of older people after hip (proximal femoral) fracture. Cochrane Database Syst Rev 2011;(8):ED000023.

94. Mak J, Wong E, Cameron I; Australian and New Zealand Society for Geriatric Medicine. Australian and New Zealand Society for Geriatric Medicine: Position statement - orthogeriatric care. Australas J Ageing 2011;30:162-9.

95. Donohue K, Hoevenaars R, McEachern J, Zeman E, Mehta S. Home-based multidisciplinary rehabilitation following hip fracture surgery: what is the evidence? Rehabil Res Pract 2013;2013:875968.

96. Mehta SP, Roy JS. Systematic review of home phys- 
iotherapy after hip fracture surgery. J Rehabil Med 2011;43:477-80.

97. Turunen K, Salpakoski A, Edgren J, Tormakangas T, Arkela M, Kallinen M, et al. Physical activity after a hip fracture: effect of a multicomponent homebased rehabilitation program: a secondary analysis of a randomized controlled trial. Arch Phys Med Rehabil 2017;98:981-8.

98. Tseng MY, Liang J, Shyu YI, Wu CC, Cheng HS, Chen $\mathrm{CY}$, et al. Effects of interventions on trajectories of health-related quality of life among older patients with hip fracture: a prospective randomized controlled trial. BMC Musculoskelet Disord 2016;17:114.

99. Karlsson A, Berggren M, Gustafson Y, Olofsson B, Lindelof N, Stenvall M. Effects of geriatric interdisciplinary home rehabilitation on walking ability and length of hospital stay after hip fracture: a randomized controlled trial. J Am Med Dir Assoc 2016;17:464.e9-464.e15.

100. Salpakoski A, Tormakangas T, Edgren J, Kallinen M, Sihvonen SE, Pesola M, et al. Effects of a multicomponent home-based physical rehabilitation program on mobility recovery after hip fracture: a randomized controlled trial. J Am Med Dir Assoc 2014;15:361-8.

101. Orwig DL, Hochberg M, Yu-Yahiro J, Resnick B, Hawkes WG, Shardell M, et al. Delivery and outcomes of a yearlong home exercise program after hip fracture: a randomized controlled trial. Arch Intern Med 2011;171:323-31.

102. Tinetti ME, Baker DI, Gottschalk M, Williams CS, Pollack D, Garrett P, et al. Home-based multicomponent rehabilitation program for older persons after hip fracture: a randomized trial. Arch Phys Med Rehabil 1999;80:916-22.

103. Magaziner J, Hawkes W, Hebel JR, Zimmerman SI, Fox KM, Dolan M, et al. Recovery from hip fracture in eight areas of function. J Gerontol A Biol Sci Med Sci 2000;55:M498-507.

104. Fransen M, Woodward M, Norton R, Robinson E, Butler M, Campbell AJ. Excess mortality or institutionalization after hip fracture: men are at greater risk than women. J Am Geriatr Soc 2002;50:685-90.

105. Latham NK, Harris BA, Bean JF, Heeren T, Goodyear C, Zawacki S, et al. Effect of a home-based exercise program on functional recovery following rehabilitation after hip fracture: a randomized clinical trial.
JAMA 2014;311:700-8.

106. Mangione KK, Craik RL, Palombaro KM, Tomlinson SS, Hofmann MT. Home-based leg-strengthening exercise improves function 1 year after hip fracture: a randomized controlled study. J Am Geriatr Soc 2010;58:1911-7.

107. Sherrington C, Lord SR. Home exercise to improve strength and walking velocity after hip fracture: a randomized controlled trial. Arch Phys Med Rehabil 1997;78:208-12.

108. Scurrah A, Shiner CT, Stevens JA, Faux SG. Regional nerve blockade for early analgesic management of elderly patients with hip fracture: a narrative review. Anaesthesia 2018;73:769-83.

109. Munter KH, Clemmesen CG, Foss NB, Palm H, Kristensen MT. Fatigue and pain limit independent mobility and physiotherapy after hip fracture surgery. Disabil Rehabil 2018;40:1808-16.

110. Abou-Setta AM, Beaupre LA, Rashiq S, Dryden DM, Hamm MP, Sadowski CA, et al. Comparative effectiveness of pain management interventions for hip fracture: a systematic review. Ann Intern Med 2011;155:234-45.

111. Guay J, Parker MJ, Griffiths R, Kopp SL. Peripheral nerve blocks for hip fractures: a Cochrane review. Anesth Analg 2018;126:1695-704.

112. Guay J, Parker MJ, Griffiths R, Kopp S. Peripheral nerve blocks for hip fractures. Cochrane Database Syst Rev 2017;5:CD001159.

113. Rowlands M, Walt GV, Bradley J, Mannings A, Armstrong S, Bedforth N, et al. Femoral Nerve Block Intervention in Neck of Femur Fracture (FINOF): a randomised controlled trial. BMJ Open 2018;8:e019650.

114. Morrison RS, Dickman E, Hwang U, Akhtar S, Ferguson T, Huang J, et al. Regional nerve blocks improve pain and functional outcomes in hip fracture: a randomized controlled trial. J Am Geriatr Soc 2016;64:2433-9.

115. Nie H, Zhao B, Zhang YQ, Jiang YH, Yang YX. Pain and cognitive dysfunction are the risk factors of delirium in elderly hip fracture Chinese patients. Arch Gerontol Geriatr 2012;54:e172-4.

116. Mouzopoulos G, Vasiliadis G, Lasanianos N, Nikolaras G, Morakis E, Kaminaris M. Fascia iliaca block prophylaxis for hip fracture patients at risk for delirium: a randomized placebo-controlled study. J 
Orthop Traumatol 2009;10:127-33.

117. Haslam L, Lansdown A, Lee J, van der Vyver M. Survey of current practices: peripheral nerve block utilization by ED physicians for treatment of pain in the hip fracture patient population. Can Geriatr J 2013;16:16-21.

118. Abrahams MS, Aziz MF, Fu RF, Horn JL. Ultrasound guidance compared with electrical neurostimulation for peripheral nerve block: a systematic review and meta-analysis of randomized controlled trials. Br J Anaesth 2009;102:408-17.

119. Korbe S, Udoji EN, Ness TJ, Udoji MA. Ultrasoundguided interventional procedures for chronic pain management. Pain Manag 2015;5:465-82.

120. Shim JH. Is ultrasound-guided procedure entirely reliable? Korean J Anesthesiol 2017;70:487-8.

121. Balk E, Ellis AG, Di M, Adam GP, Trikalinos TA. Venous thromboembolism prophylaxis in major orthopedic surgery: systematic review update. Rockville, MD: Agency for Healthcare Research and Quality; 2017.

122. Leizorovicz A, Turpie AG, Cohen AT, Wong L, Yoo MC, Dans A, et al. Epidemiology of venous thromboembolism in Asian patients undergoing major orthopedic surgery without thromboprophylaxis. The SMART study. J Thromb Haemost 2005;3:28-34.

123. Yhim HY, Jang MJ, Bang SM, Kim KH, Kim YK, Nam $\mathrm{SH}$, et al. Incidence of venous thromboembolism following major surgery in Korea: from the Health Insurance Review and Assessment Service database. J Thromb Haemost 2014;12:1035-43.

124. Jang MJ, Bang SM, Oh D. Incidence of venous thromboembolism in Korea: from the Health Insurance Review and Assessment Service database. J Thromb Haemost 2011;9:85-91.

125. Heit JA, O'Fallon WM, Petterson TM, Lohse CM, Silverstein MD, Mohr DN, et al. Relative impact of risk factors for deep vein thrombosis and pulmonary embolism: a population-based study. Arch Intern Med 2002;162:1245-8.

126. Kuperman EF, Schweizer M, Joy P, Gu X, Fang MM. The effects of advanced age on primary total knee arthroplasty: a meta-analysis and systematic review. BMC Geriatr 2016;16:41.

127. Chang JD, Yoo JH, Lee SS, Kim TY, Jung KH, Kim YK. Bipolar hemiarthroplasty for hip fractures in patients aged over 90 years: the factors influencing the postoperative mortality. J Korean Hip Soc 2010;22:28390.

128. Monticone M, Ambrosini E, Brunati R, Capone A, Pagliari G, Secci C, et al. How balance task-specific training contributes to improving physical function in older subjects undergoing rehabilitation following hip fracture: a randomized controlled trial. Clin Rehabil 2018;32:340-51.

129. Tang Y, Wang K, Shi Z, Yang P, Dang X. A RCT study of rivaroxaban, low-molecular-weight heparin, and sequential medication regimens for the prevention of venous thrombosis after internal fixation of hip fracture. Biomed Pharmacother 2017;92:982-8.

130. Wald HL, Ma A, Bratzler DW, Kramer AM. Indwelling urinary catheter use in the postoperative period: analysis of the national surgical infection prevention project data. Arch Surg 2008;143:551-7.

131. Kuy S, Gupta R, Roy C, Awad S. Incidence of catheterassociated urinary tract infections with compliance with preventive guidelines. JAMA Surg 2020;155:6612.

132. Halleberg Nyman M, Gustafsson M, Langius-Eklof A, Johansson JE, Norlin R, Hagberg L. Intermittent versus indwelling urinary catheterisation in hip surgery patients: a randomised controlled trial with costeffectiveness analysis. Int J Nurs Stud 2013;50:158998.

133. Skelly JM, Guyatt GH, Kalbfleisch R, Singer J, Winter L. Management of urinary retention after surgical repair of hip fracture. CMAJ 1992;146:1185-9.

134. Michelson JD, Lotke PA, Steinberg ME. Urinarybladder management after total joint-replacement surgery. N Engl J Med 1988;319:321-6.

135. Center JR, Bliuc D, Nguyen TV, Eisman JA. Risk of subsequent fracture after low-trauma fracture in men and women. JAMA 2007;297:387-94.

136. Colon-Emeric C, Kuchibhatla M, Pieper C, Hawkes W, Fredman L, Magaziner J, et al. The contribution of hip fracture to risk of subsequent fractures: data from two longitudinal studies. Osteoporos Int 2003;14:879-83.

137. Kanis JA, Johnell O, De Laet C, Johansson H, Oden A, Delmas $\mathrm{P}$, et al. A meta-analysis of previous fracture and subsequent fracture risk. Bone 2004;35:375-82.

138. Klotzbuecher CM, Ross PD, Landsman PB, Abbott 
TA 3rd, Berger M. Patients with prior fractures have an increased risk of future fractures: a summary of the literature and statistical synthesis. J Bone Miner Res 2000;15:721-39.

139. Solomon DH, Finkelstein JS, Katz JN, Mogun H, Avorn J. Underuse of osteoporosis medications in elderly patients with fractures. Am J Med 2003;115:398400.

140. Bawa HS, Weick J, Dirschl DR. Anti-osteoporotic therapy after fragility fracture lowers rate of subsequent fracture: analysis of a large population sample. J Bone Joint Surg Am 2015;97:1555-62.

141. Soong YK, Tsai KS, Huang HY, Yang RS, Chen JF, Wu PC, et al. Risk of refracture associated with compliance and persistence with bisphosphonate therapy in Taiwan. Osteoporos Int 2013;24:511-21.

142. Kim TY, Ha YC, Kang BJ, Lee YK, Koo KH. Does early administration of bisphosphonate affect fracture healing in patients with intertrochanteric fractures? J Bone Joint Surg Br 2012;94:956-60.

143. Lyles KW, Colon-Emeric CS, Magaziner JS, Adachi JD, Pieper CF, Mautalen C, et al. Zoledronic acid and clinical fractures and mortality after hip fracture. N Engl J Med 2007;357:1799-809.

144. Li Y, Zhao WB, Wang DL, He Q, Li Q, Pei FX, et al. Treatment of osteoporotic intertrochanteric fractures by zoledronic acid injection combined with proximal femoral nail anti-rotation. Chin J Traumatol 2016;19:259-63.

145. Beaupre LA, Morrish DW, Hanley DA, Maksymowych WP, Bell NR, Juby AG, et al. Oral bisphosphonates are associated with reduced mortality after hip fracture. Osteoporos Int 2011;22:983-91.

146. Cecilia D, Jodar E, Fernandez C, Resines C, Hawkins F. Effect of alendronate in elderly patients after low trauma hip fracture repair. Osteoporos Int 2009;20:903-10.

147. Osaki M, Tatsuki K, Hashikawa T, Norimatsu T, Chiba $\mathrm{K}$, Motokawa S, et al. Beneficial effect of risedronate for preventing recurrent hip fracture in the elderly Japanese women. Osteoporos Int 2012;23:695-703.

148. Peng J, Liu Y, Chen L, Peng K, Xu Z, Zhang D, et al. Bisphosphonates can prevent recurrent hip fracture and reduce the mortality in osteoporotic patient with hip fracture: a meta-analysis. Pak J Med Sci 2016;32:499-504.
149. Lee SY, Jung SH, Lee SU, Ha YC, Lim JY. Can bisphosphonates prevent recurrent fragility fractures? A systematic review and meta-analysis of randomized controlled trials. J Am Med Dir Assoc 2018;19:384-90.

150. Kim C, Sung J, Lee JH, Kim WS, Lee GJ, Jee S, et al. Clinical practice guideline for cardiac rehabilitation in Korea. Ann Rehabil Med 2019;43:355-443.

151. Invernizzi M, de Sire A, D'Andrea F, Carrera D, Reno F, Migliaccio S, et al. Effects of essential amino acid supplementation and rehabilitation on functioning in hip fracture patients: a pilot randomized controlled trial. Aging Clin Exp Res 2019;31:1517-24.

152. Torres MJ, Feart C, Samieri C, Dorigny B, Luiking $\mathrm{Y}$, Berr C, et al. Poor nutritional status is associated with a higher risk of falling and fracture in elderly people living at home in France: the Three-City cohort study. Osteoporos Int 2015;26:2157-64.

153. Miyanishi K, Jingushi S, Torisu T. Mortality after hip fracture in Japan: the role of nutritional status. J Orthop Surg (Hong Kong) 2010;18:265-70.

154. Gumieiro DN, Rafacho BP, Goncalves AF, Tanni SE, Azevedo PS, Sakane DT, et al. Mini Nutritional Assessment predicts gait status and mortality 6 months after hip fracture. Br J Nutr 2013;109:1657-61.

155. Malafarina V, Reginster JY, Cabrerizo S, Bruyere O, Kanis JA, Martinez JA, et al. Nutritional status and nutritional treatment are related to outcomes and mortality in older adults with hip fracture. Nutrients 2018;10:555.

156. Paillaud E, Bories PN, Le Parco JC, Campillo B. Nutritional status and energy expenditure in elderly patients with recent hip fracture during a 2-month follow-up. Br J Nutr 2000;83:97-103.

157. Hedstrom M. Hip fracture patients, a group of frail elderly people with low bone mineral density, muscle mass and IGF-I levels. Acta Physiol Scand 1999;167:347-50.

158. Mahran DG, Farouk O, Ismail MA, Alaa MM, Eisa A, Ragab II. Effectiveness of home based intervention program in reducing mortality of hip fracture patients: a non-randomized controlled trial. Arch Gerontol Geriatr 2019;81:8-17.

159. Lonnie M, Hooker E, Brunstrom JM, Corfe BM, Green MA, Watson AW, et al. Protein for life: review of optimal protein intake, sustainable dietary sources and the effect on appetite in ageing adults. Nutri- 
ents 2018;10:360.

160. Campbell WW, Trappe TA, Jozsi AC, Kruskall LJ, Wolfe RR, Evans WJ. Dietary protein adequacy and lower body versus whole body resistive training in older humans. J Physiol 2002;542(Pt 2):631-42.

161. World Health Organization. Protein and amino acid requirements in human nutrition. Geneva, Swizerland: World Health Organization; 2002.

162. Deutz NE, Bauer JM, Barazzoni R, Biolo G, Boirie Y, Bosy-Westphal A, et al. Protein intake and exercise for optimal muscle function with aging: recommendations from the ESPEN Expert Group. Clin Nutr 2014;33:929-36.

163. Avenell A, Smith TO, Curtain JP, Mak JC, Myint PK. Nutritional supplementation for hip fracture aftercare in older people. Cochrane Database Syst Rev 2016;11:CD001880.

164. Espaulella J, Guyer H, Diaz-Escriu F, Mellado-Navas JA, Castells M, Pladevall M. Nutritional supplementation of elderly hip fracture patients: a randomized, double-blind, placebo-controlled trial. Age Ageing 2000;29:425-31.

165. Tkatch L, Rapin CH, Rizzoli R, Slosman D, Nydegger V, Vasey H, et al. Benefits of oral protein supplementation in elderly patients with fracture of the proximal femur. J Am Coll Nutr 1992;11:519-25.

166. Aquilani R, Zuccarelli Ginetto C, Rutili C, Pisano P, Pasini E, Baldissarro E, et al. Supplemented amino acids may enhance the walking recovery of elderly subjects after hip fracture surgery. Aging Clin Exp Res 2019;31:157-60.

167. Wyers CE, Reijven PL, Breedveld-Peters JJ, Denissen KF, Schotanus MG, van Dongen MC, et al. Efficacy of nutritional intervention in elderly after hip fracture: a multicenter randomized controlled trial. J Gerontol A Biol Sci Med Sci 2018;73:1429-37.

168. Niitsu M, Ichinose D, Hirooka T, Mitsutomi K, Morimoto Y, Sarukawa J, et al. Effects of combination of whey protein intake and rehabilitation on muscle strength and daily movements in patients with hip fracture in the early postoperative period. Clin Nutr 2016;35:943-9.

169. Ekinci O, Yanik S, Terzioglu Bebitoglu B, Yilmaz Akyuz E, Dokuyucu A, Erdem S. Effect of Calcium $\beta$-Hydroxy- $\beta$-Methylbutyrate (CaHMB), vitamin D, and protein supplementation on postoperative immobilization in malnourished older adult patients with hip fracture: a randomized controlled study. Nutr Clin Pract 2016;31:829-35.

170. Beaupre LA, Jones CA, Saunders LD, Johnston DW, Buckingham J, Majumdar SR. Best practices for elderly hip fracture patients: a systematic overview of the evidence. J Gen Intern Med 2005;20:1019-25.

171. Swift C, Ftouh S, Langford P, Chesser TS, Johanssen A. Interdisciplinary management of hip fracture. Clin Med (Lond) 2016;16:541-4.

172. Yoo JI, Ha YC, Lim JY, Kang H, Yoon BH, Kim H. Early rehabilitation in elderly after arthroplasty versus internal fixation for unstable intertrochanteric fractures of femur: systematic review and meta-analysis. J Korean Med Sci 2017;32:858-67.

173. Smith TO, Collier T, Sheehan KJ, Sherrington C. The uptake of the hip fracture core outcome set: analysis of 20 years of hip fracture trials. Age Ageing 2019;48:595-8.

174. Haywood KL, Griffin XL, Achten J, Costa ML. Developing a core outcome set for hip fracture trials. Bone Joint J 2014;96-B:1016-23.

175. Armstrong MJ, Mullins CD, Gronseth GS, Gagliardi AR. Impact of patient involvement on clinical practice guideline development: a parallel group study. Implement Sci 2018;13:55.

176. National Clinical Guideline Centre. The management of hip fracture in adults [Internet]. London, UK: National Clinical Guideline Centre; 2011 [cited 2021 May 24]. Available from: https://www.nice. org.uk/guidance/cg124/evidence/full-guidelinepdf-183081997. 